\title{
Pension design with a large informal labor market: evidence from Chile
}

\author{
Clement Joubert* ${ }^{\dagger}$
}

First draft: November 1st, 2009

This draft: January 10th, 2011

\begin{abstract}
Pension design in developing countries must take into account that both contributory and non-contributory pension schemes can affect incentives to work informally, with important fiscal consequences. The extent of this problem depends on the nature of the informal labor market: residual or competitive? Linked administrative and self-reported data from Chile on employment histories, earnings and savings are used to estimate a dynamic behavioral model in which a couple faces a labor market composed of a covered sector, that is subject to mandatory pension contributions, and an uncovered sector of self-employed and informal jobs. The estimated model is used to determine the extent of labor market segmentation, and whether mandatory pension contributions and minimum pension benefits could reduce the pension system's coverage rate and crowd out private savings. Then, an expanded safety net, recently implemented in Chile as a response to low pension coverage rates, is introduced into the model to quantify its effects on labor supply, savings and the government budget.
\end{abstract}

JEL Classification: J26, J08, E21, E26

\footnotetext{
${ }^{*}$ Assistant Professor, Department of Economics, University of North Carolina at Chapel Hill (joubertc@email.unc.edu)

${ }^{\dagger}$ I thank Petra Todd, Ken Wolpin, Dirk Krueger, and the participants at the Penn Macro Club and the Empirical Micro Lunch. I gratefully acknowledge financial support from the TRIO (PARC/Boettner/NICHD) Pilot Project Competition and from the Center for Retirement Research at Boston College. Formerly circulated under the title "Dynamic labor supply and saving incentives in privatized pension systems: evidence from Chile"
} 


\section{Introduction}

Over the last three decades, many countries in Latin America and Eastern Europe, opted to completely overhaul their pension systems by introducing privately-managed individual accounts-based systems with strong ties between contributions and pensions. ${ }^{1}$ Chile was one of the earliest countries to make this transition in 1981, and its pension system strongly influenced the design of many other countries' systems. Proponents of privatization hoped, among other benefits, that a system based on individual accounts would create smaller labor distortions and improve participation in the pension system (Corsetti and Schmidt-Hebbel (1997)). However, 27 years later, after recognizing that a large fraction of its workforce was effectively not covered by the pension system, Chile shifted gears by implementing in 2008 a dramatic expansion of the role of the State as a retirement benefit provider. As non-contributory pension benefits such as minimum pensions can create incentives to avoid the formal labor market, some worry that this reform could further reduce pension coverage and be fiscally costly.

This paper explores aspects of pension system design in the presence of a large informal labor market. To do so, I develop and estimate a dynamic model of household savings and labor supply in a dual labor market, using Chilean data. The parameter estimates reveal some labor market segmentation between the formal and informal labor markets but only for low educated workers. They also imply that returns to experience, though different in the two sectors, do not depend on the sector in which the worker accumulated her skills. I simulate the effects of an increase in state-provided non-contributory benefits modeled after the 2008 Chilean pension reform and find a reduction of labor force participation at older ages together with a moderate transfer of workers from the formal to the informal labor market, despite a benefit design aimed at limiting implicit marginal tax rates. Both effects contribute to the large increase in the pension system's fiscal cost predicted by the counterfactual simulations.

\footnotetext{
${ }^{1}$ For example (year of the reform): Peru (1993), Argentina (1994), Mexico (1997), Hungary(1998), Poland (1999), Bulgaria (2000).
} 
A priori, the effects of pension system rules on pension coverage and the fiscal cost of old age benefits should be in large part determined by the propensity of workers to respond to incentives by switching between formal jobs, in which they contribute to the pension system, and informal jobs. The importance of this margin depends crucially on whether there are barriers to entry into the formal labor market. A long tradition in labor and development economics has posited that work in the formal sector is rationed. Though differences in estimated earning equations in the two sectors were initially taken as a validation of the segmentation hypothesis, it was later argued that comparative advantages and compensating wage differentials could lead to distinct wage equations without rationing (Dickens and Lang (1985), Heckman and Hotz (1986), Magnac (1991), Gindling (1991)). More recent papers, following descriptive work by Maloney (1999), have examined panel aspects of the data such as sector transitions (Gong et al. (2004)) and wage differentials (Gong and Van Soest (2002)) using dynamic multinomial logit models with random effects. My model uses both sector transitions and wage differentials to identify the extent of segmentation within a dynamic structural framework to derive its implications for policy. In the model, although workers can always work in the uncovered sector, I allow the probability of receiving a covered job offer to be less than one and to depend on individual characteristics, including the number of years already worked in the covered sector. In addition, incentives to work in the covered sector are dynamically affected by labor supply decisions made in previous periods as spouses endogenously accumulate sector-specific human capital. The other dynamic structural models that incorporate an informal labor market to study pension design do not allow for segmentation, rather assuming a priori that workers can move freely between sectors (Valdés-Prieto (2008), Velez-Grajales (2009)). An exception is Robalino et al. (2008) who specify and estimate a dynamic stochastic model, in which agents can save privately and exert effort to increase their probability of working in the formal sector, to estimate the potential effect of a large set of social insurance policies in the context of Brasil. They estimate preference parameters using age-profiles of the fraction of individuals in the covered, uncovered, unemployed and retired states, but do not use data on wages, assets, sector-specific experience or longitudinal 
transitions.

The model incorporates two other important features that interact with pension system rules. The first is the saving decision which generates an implicit choice of portfolio between a taxable, liquid asset and tax-deferred, illiquid pension savings. How that tradeoff evolves over the life cycle as a function of the relative strength of the precautionary and retirement saving motive has been studied in the context of Individual Retirement Accounts (IRAs) (Gale and Scholz (1994), Engen et al. (1994), Engen et al. (1996), Hubbard et al. (1995)...). More recently, Dammon et al. (2004) and Gomes et al. (2005), look at the optimal life cycle portfolio choice between taxable and tax-deferred accounts, and evaluate the welfare cost from contributing at a suboptimal rate. Importantly, the level of accumulated private and pension savings also influences labor sector choice by changing the value of additional illiquid pension contributions. The second mechanism is the joint labor supply decision made by the spouses. Van der Klaauw and Wolpin (2008) highlight the importance of allowing for income risk pooling within the household to accurately study the incentives created by social pension programs. ${ }^{2}$

I estimate the parameters of the earnings offer function, of preferences and of the probability of receiving a covered job offer using the Method of Simulated Moments (McFadden (1989)). I use a unique data set collected for the purpose of analyzing social protection in Chile, and the pension system in particular. The data is composed of a longitudinal survey ("Encuesta de Proteccion Social" or EPS) linked with administrative data from the pension system's regulatory agency. ${ }^{3}$ The survey data include retrospective employment histories, as well as self-reported household labor earnings and household assets collected in 2002, 2004 and 2006. The administrative data contain the longitudinal history of pension savings of the respondents since the 1980 pension reform.

Using the estimated model, I evaluate ex-ante the impact of the major expansion of the system's safety net passed in 2008, that provides a good illustration of the tradeoffs

\footnotetext{
${ }^{2}$ Other recent examples include Gustman and Steinmeier (2000), Gustman and Steinmeier (2002), Blau and Gilleskie (2006).

${ }^{3}$ Superintendencia de Administradoras de Fondos de Pensiones (SAFP).
} 
faced by policy makers. Concern over old age poverty among these low-contribution workers was the major impetus behind the reform. However, as pointed in Piggot et al. (2009), a generous safety net can create additional disincentives for pension contributions. First, by reducing the marginal value of consumption in retirement and second, by imposing an effective marginal tax (EMT) on pension contributions if these reduce the benefit received by the worker. ${ }^{4}$ Before the 2008 reform, Chile's safety net was composed of a means-tested welfare pension (pension asistencial, PASIS) and a minimum pension guarantee (MPG) for individuals with 20 or more years of contributions to their individual pension accounts (see figure 1). These both took the form of top-ups, so that workers eligible to either benefit faced an effective marginal tax of $100 \%$, as additional contributions to their account would not increase the level of their pension. ${ }^{5}$ The 2008 reform implements a unified safety net which guarantees a minimum pension level regardless of the number of years of contribution. For each peso of self-financed pension, the benefit is reduced by 0.3 pesos, lowering the implicit marginal tax rate on pension contributions to about 37\%. However, this gradual reduction can also significantly increase the fiscal burden to the government.

Counterfactual simulations suggest a very low projected fiscal cost for the pre-2008 system, with only about $1.5 \%$ of males and $5 \%$ of females in the sample qualifying for the guaranteed minimum pension benefits. The low level of the minimum pension, the stringent 20 years of contribution eligibility requirement and the high historical rates of return on Chilean pension funds explain this result. In contrast, the more generous safety net from the 2008 reform will benefit more than $20 \%$ of the sample, be six times as costly to the government and generate a small reduction in coverage and female labor force participation.

In addition to analyzing ex-ante the impact of the 2008 reform, I perform a second policy experiment that assesses the disincentives implied by the estimated model for participation

\footnotetext{
${ }^{4}$ The effect of the marginal tax created by minimum pensions on retirement decisions is analyzed in the context of Spain by Jimenez-Martin and Sanchez-Martin (2007) and Sanchez-Martin (2008).

${ }^{5}$ In a top-up design, if the level of the pension afforded by the worker's contributions is below the minimum pension, the benefit paid by the government is equal to the difference between the two.
} 


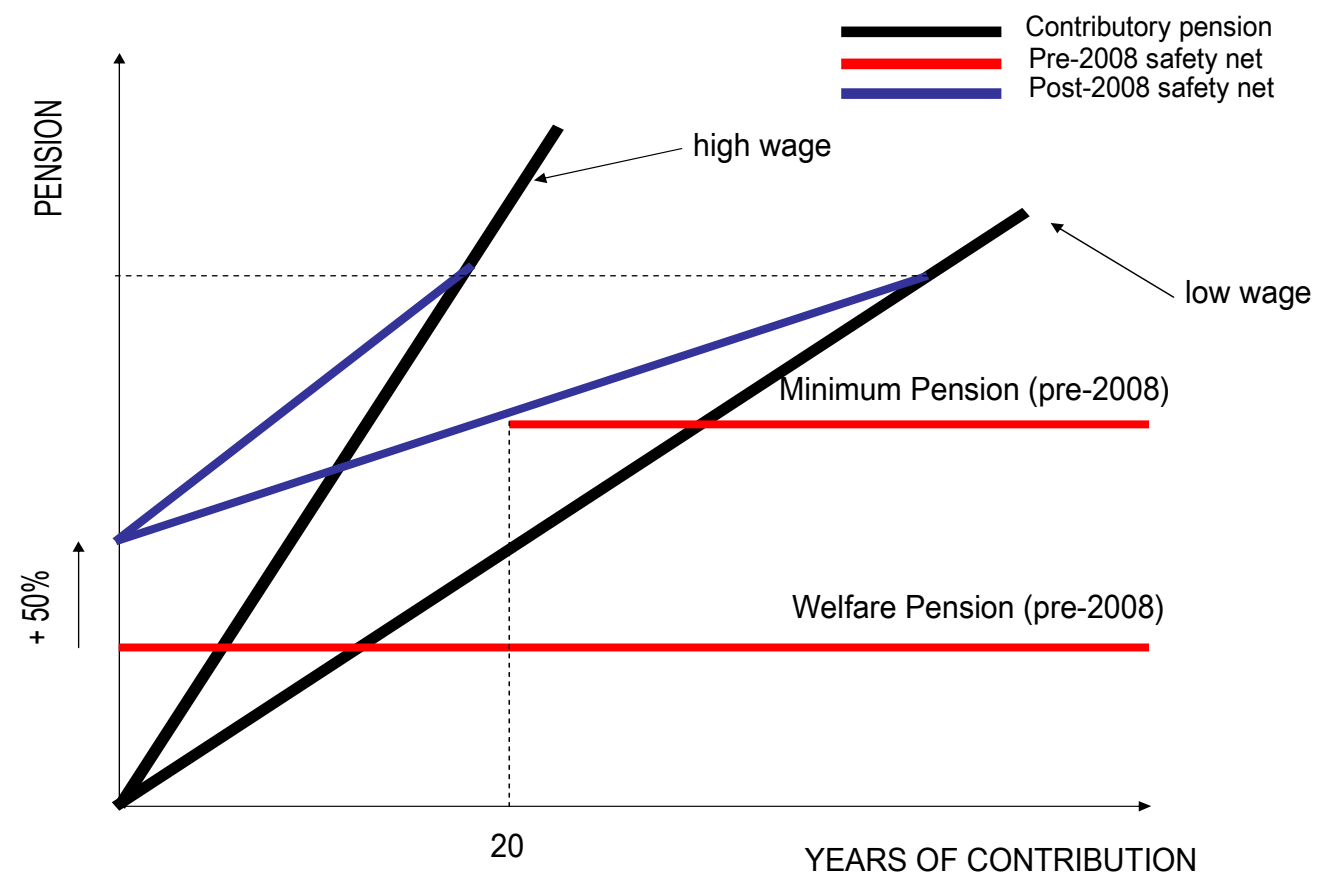

Figure 1: The 2008 reform of the Chilean pension safety net

in the pension program created by mandatory pension contributions. In Chile, salaried workers are required to contribute $10 \%$ of their wages to their pension account. ${ }^{6}$ The very low level of additional voluntary pension contributions above the required level of $10 \%$ suggests that this lower bound on the saving rate is binding for most workers. ${ }^{7}$ A higher mandatory contribution rate could increase household savings and reduce the fiscal cost of the safety net, unless it discourages participation in pension covered jobs too much. Conversely, a lower contribution rate could improve pension coverage, but would potentially increase government liabilities. The second experiment changes the mandatory contribution rate from $10 \%$ to values ranging from $5 \%$ to $20 \%$. I find that the government can significantly increase

\footnotetext{
${ }^{6}$ In addition, $2.6 \%$ of administrative fees and disability insurance premium as well as $7 \%$ of contributions to a health insurance scheme are deducted from the payroll.

${ }^{7}$ Fewer than two percent of pension system members had positive balances in their voluntary contributions account in 2005.
} 
total household savings by increasing the required contribution rate. Faced with a contribution rate of $15 \%$ instead of $10 \%$, households partially offset the higher mandatory pension contributions by reducing their private savings, but still end up saving $14 \%$ more overall. However, it also lowers pension system coverage by 5 percentage points as people leave the covered sector for the uncovered sector.

The paper is structured as follows. Section 2 of the paper provides background information on the Chilean Pension System. Section 3 lays out the structural model. Section 4 describes the data, estimation procedure, parameter estimates and model fit. Section 5 shows results from the policy experiments. Section 6 concludes.

\section{Background: the Chilean Pension System}

\subsection{The crisis of the old Pay-as-you-go system}

Before 1981, Chile had a heterogeneous Social Security system composed of up to 32 different institutions called "Cajas de Prevision", that covered different professions and categories of the population. Each specified different contribution and benefit rules. Originally designed as partially-funded, the system evolved into a pay-as-you-go program, with a chronic deficit financed by the State that represented $40 \%$ of payments in 1980 . Despite repeated attempts at reforms dating back to the fifties, the financial imbalances of the pension system deteriorated. The system was caught in a vicious circle by which deficits would lead to higher contributions (over $50 \%$ of a worker's monthly remuneration in $1974^{8}$ ), higher contributions would result in increased payment evasion (the ratio of active contributors over people in work fell from 83 in 1973 to 71 in 1980), which accentuated the decline in the Contributorsto-Pensioners ratio (3.5 in 1973, 2.2 in 1980) and the system's budget deficit.

\footnotetext{
${ }^{8}$ Note that this number refers to a global contribution rate which financed pensions but also health benefits and industrial accidents, among other things.
} 


\subsection{The Chilean Pension System}

On November 4th 1980, Chile created a new Pension System, known as "AFP" 9 system. The previous system was reorganized into a unified institution named Institute of Social Security Normalization (INP) which to this day manages the old system's pensioners and workers who decided to remain affiliated to the old system. In order to encourage transfers, workers who opted for the new system received an increase in net income of $12.6 \%$ (which corresponds to the new contribution rate plus commissions or fees) and the benefits accrued under the old system were recognized by issuing a "recognition bond" payable upon retirement.

The main component of the new AFP Pension system is a savings program based on defined-contribution individual accounts. The program is mandatory for salaried workers and voluntary for the self-employed. Affiliated workers must pay $10 \%$ of their monthly wages in a tax-deferred pension account which is locked until retirement. The contributions are capped at $60 \mathrm{UFs}^{10}$. In addition to the $10 \%$ pension contribution, workers must pay a contribution of $7 \%$ for health services, $0.8 \%$ for a disability and survivorship insurance, and $2.6 \%$ to the pension fund manager as a commision or fee.

The worker can choose from a number of pension fund administrators (the "AFP"s) who manage the savings deposited on the account and invest them on the financial markets. The number of AFPs has changed over the years, reaching 32 in 1997 but was down to 5 in 2008. Initially, AFPs were required to invest all of the funds in government bonds, but they have gradually been allowed to offer a broader array of investment choices, including foreign assets and stocks. In addition, since 2002, each AFP must offer 5 portfolio options, called multifunds, to their affiliates. The funds are labeled A to E with an increasing weight on fixed-income assets. By default, older workers are assigned to a more conservative portfolio (D or E).

Workers can access their pension savings at 65 years old for men and 60 years old for

\footnotetext{
${ }^{9}$ AFP: Administradoras de Fondos de Pensiones, or Pension Funds Administrators

${ }^{10}$ UFs or Unidades de Fomento are indexed on inflation. The value of the UF as of December 2004 was $\$ 17,317$ pesos (US\$31)
} 
women. They have three withdrawal options: Programmed Withdrawals (Retiro Programado), purchase an annuity from an insurance company (Renta Vitalicia), or a mix of phased withdrawals for a period of time and a deferred lifetime annuity. The law allows for early retirement, provided that the worker can obtain a pension equal to or greater than $110 \%$ of the minimum pension guaranteed by the State $^{11}$. Before 2008, the state provided retirement income transfers through two mechanisms. A welfare or assistance pension (pension asistencial or PASIS), equal to about $1 / 3$ of the minimum wage ${ }^{12}$ was provided to individuals above 65 years of age, irrespective of their contribution history, provided that their earnings and their household's per capita earnings per capita were both below that level. The second transfer was a minimum pension guarantee (MPG) equal to about twice the PASIS: individuals with more than 20 years of contribution would receive the MPG if their accumulated contributions could not finance a higher pension. Both these benefits took the form of a top-up: the benefit was equal to the difference between the guaranteed level and the pension financed by the worker's account.

\subsection{The 2008 Reform of the Safety Net}

The analysis of histories of pension contributions at the micro level revealed that about half of the working population was contributing to the system too little to finance a minimum pension or to qualify for the State MPG. This led to an overhaul of the system of minimum pensions paid by the State. The reform also tackled other problems such as insufficient price competition in the AFP industry or gender equity, but I focus in this work on the reform of the eligibility and level of the safety-net. The 2008 reform replaced the PASIS and MPG with a "New Solidarity Pillar" comprised of a unique means-tested welfare pension which guarantees to all individuals in the $60 \%$ less affluent fraction of the population a pension of 75000 pesos per month. ${ }^{13}$ This represents an increase of nearly $50 \%$ with respect to the PASIS. The

\footnotetext{
${ }^{11}$ The pension must also be equal to or greater than $50 \%$ of the average taxable income for the last 10 working years

${ }^{12}$ In 2007, the PASIS was 44.186 per month for workers between 65 and $70,47.103$ between 70 and 75 , and 51.503 between 75 and 80 (82, 87 and 95 dollars per month respectively).

${ }^{13}$ The current level is 60000 pesos but will be increased gradually until 2012
} 
main innovation is that instead of constituting a floor pension, the benefits are gradually reduced, at a rate of $30 \%$, for workers with some accumulated pension contributions. That is, a worker who can finance a pension of 100,000 pesos per month with the funds accumulated in her individual account will receive a benefit equal to $75,000-(100,000 * 0.3)=45,000$. Her total pension will then be 145,000 pesos per month. Before the reform, eligible workers effectively faced an implicit marginal tax rate of 100\%: additional contributions would not increase the level of her pension at retirement. The means-tested welfare pension also created disincentives for participation as workers anticipating to benefit from it would not gain from saving into the system. The new system ensures that an additional contribution always increase the level of the retirement pension, and it maintains a constant implicit marginal tax rate of about $37 \%$ on additional contributions. 


\section{The Model}

\subsection{Description of the Model}

The model represents the decision problem of a married or unmarried couple. I use the husband/wife terminology in both cases for simplicity. The optimization problem starts when the couple is formed $\left(t=t_{0}\right)$. Initial conditions are comprised of work experiences and schooling levels of both spouses and the household's assets. A period corresponds to a calendar year and is indexed by the husband's age. Spouses are assumed to remain together until they both die at $t=t_{D}$.

\subsubsection{Decisions}

To keep the model tractable, I assume that both spouses claim their pension benefits and stop working at $t=t_{R}$. At each working age $t \in\left\{t_{0}, \ldots t_{R}-1\right\}$, households make two decisions: the household consumption decision $c_{t}$ and a joint labor force participation decision $d_{t}=\left(d_{t}^{H}, d_{t}^{W}\right)$, where $H, W$ refers to Husband and Wife. Three employment options are available to spouse $j \in\{H, W\}$ : to work in the covered sector $\left(d_{t}^{j}=1\right)$, to work in the uncovered sector $\left(d_{t}^{j}=2\right)$, or to stay home $\left(d_{t}^{j}=3\right)$. After retirement, both spouses stay at home $\left(d_{t}=(3,3)\right)$ and only make a consumption decision.

\subsubsection{Preferences}

Couples form a unitary household with a single common period utility function. They care about total household consumption through a CRRA utility function. They also care about whether each spouse works or not through non-pecuniary benefits derived from leisure denoted by $\delta^{H}$ and $\delta^{W}$. Finally, they pay a cost when switching between covered and uncovered sectors $\left(\phi_{s}^{H}, \phi_{s}^{W}\right)$, and when returning to work after a period at home $\left(\phi_{a}^{H}, \phi_{a}^{W}\right)$. 
The period utility function is given by:

$$
\begin{aligned}
\forall t \in\left\{t_{0}, t_{D}\right\}, & \\
u\left(c_{t}, d_{t}\right) & =\frac{c_{t}^{1-\sigma}}{1-\sigma} \\
& +\left(\delta^{H}+\epsilon_{t}^{H}\right) \cdot I_{\left\{d_{t}^{H}=3\right\}} \\
& +\left(\delta^{W}+\epsilon_{t}^{W}\right) \cdot I_{\left\{d_{t}^{W}=3\right\}} \\
& +\phi_{s}^{H} \cdot\left(I_{\left\{d_{t}^{H}=1, d_{t-1}^{H}=2\right\}}+I_{\left\{d_{t}^{H}=2, d_{t-1}^{H}=1\right\}}\right)+\phi_{a}^{H} \cdot I_{\left\{d_{t}^{H} \neq 3, d_{t-1}^{H}=3\right\}} \\
& +\phi_{s}^{W} \cdot\left(I_{\left\{d_{t}^{W}=1, d_{t-1}^{W}=2\right\}}+I_{\left\{d_{t}^{W}=2, d_{t-1}^{W}=1\right\}}\right)+\phi_{a}^{W} \cdot I_{\left\{d_{t}^{W} \neq 3, d_{t-1}^{W}=3\right\}}
\end{aligned}
$$

where the shocks to the value of leisure are assumed to be distributed normally and to be uncorrelated over time:

$$
\left(\epsilon_{t}^{H}, \epsilon_{t}^{W}\right) \sim \operatorname{iidN}\left(0, \Sigma_{p}\right)
$$

The model's state variables are the following: $a_{t}$ denotes the household's non-retirement or private savings at age $t ; B_{t}^{H}$ and $B_{t}^{W}$ are the balances on the retirement accounts of the two spouses at age $t ; X_{U, t}^{H}, X_{U, t}^{W}, X_{C, t}^{H}$ and $X_{C, t}^{W}$ are the four stocks of sector-specific experience, with the subscripts $U$ and $C$ denoting the uncovered and covered labor sectors. They correspond to the number of years each spouse has worked in each sector up to period t. $E^{H}$ and $E^{W}$ are the schooling levels of the spouses. $d_{t-1}$ is the pair of labor decisions in the previous period. $c$ is the birth cohort of the husband.

Lifetime preferences are additively separable over time and can be expressed recursively as a function of the state variables:

$$
\begin{aligned}
& \forall t \in\left\{t_{0}, t_{D}\right\} \\
& \quad V_{t}\left(a_{t},\left\{B_{t}^{i}\right\}_{i},\left\{E^{i}\right\}_{i},\left\{X_{j, t}^{i}\right\}_{i, j}, d_{t-1} ; c\right)= \\
& \quad u\left(c_{t}, d_{t}\right)+\beta E V_{t+1}\left(a_{t+1},\left\{B_{t+1}^{i}\right\}_{i},\left\{E^{i}\right\}_{i},\left\{X_{j, t+1}^{i}\right\}_{i, j}, d_{t-1} ; c\right)
\end{aligned}
$$


where $i \in\{H, W\}$ is the spouse-specific subscript, $j \in\{U, C\}$ is the sector-specific subscript and $E V_{t+1}$ is the so-called Emax function that gives expected future utility as a function of current period state variables.

\subsubsection{Household Income}

Households face a two-sector labor market with a covered and an uncovered sector. Each spouse may receive a stochastic earnings offer from the covered sector that depends on her level of schooling, sector-specific experience stocks and the birth cohort of the husband. Each spouse also receives a stochastic earnings offer from the uncovered sector with probability 1. The probability $\Gamma_{t}^{i}$ for spouse $i$ to receive an earnings offer from the covered sector in period $t$ is a logistic function of education, the number of years of covered experience, and having been employed in the covered sector in the previous period:

$$
\begin{aligned}
& \forall i \in\{H, W\}, t \in\left\{t_{0}, t_{R}\right\}, \\
& \quad \Gamma_{t}^{i}=\left(1+\exp \left\{-\left(\gamma^{i}+\gamma_{\operatorname{cov}}^{i} I_{\left\{d_{t-1}^{i}=1\right\}}+\gamma_{E}^{i} E^{i}+\gamma_{X P}^{i} X_{C}^{i}\right)\right\}\right)^{-1}
\end{aligned}
$$

The log-earnings offers (for spouse $i \in\{H, W\}$, in sector $j \in\{C, U\}$ ) are given by:

$$
w_{j, t}^{i}=\alpha_{j}^{i}+\theta_{c}^{j} \cdot c+\theta_{E, j}^{i} \cdot E^{i}+\theta_{X, j}^{i}(E) \cdot\left(X_{j}^{i}+\tau_{X P}^{j} X_{-j}^{i}\right)+\epsilon_{j, t}^{i}
$$

where $\alpha_{j}^{i}$ is a gender- and sector-specific constant, $\theta_{c}^{i}$ a sector-specific cohort effect, $\theta_{E, j}$ the returns to schooling, $\theta_{X, j}^{i}(E)$ are the returns to experience, and $\tau_{X P}^{j} \in[0,1]$ captures the transferability of cross-sector experience. $\epsilon_{j, t}^{i}$ is an iid sector-specific earnings offer shock that is uncorrelated accross time-periods and potentially correlated within a household:

$$
\left(\epsilon_{j, t}^{i}\right)_{j=U, C}^{i=H, W} \sim N\left(0, \Sigma_{o}\right)
$$


The total household disposable labor income $y_{t}$ is the sum of accepted earnings offers, net of contributions:

$$
y_{t}=\sum_{i \in\{H, W\}}\left((1-\tau) \cdot w_{C, t}^{i} \cdot I_{\left\{d_{t}^{i}=1\right\}}+w_{U, t}^{i} \cdot I_{\left\{d_{t}^{i}=2\right\}}\right)
$$

where $\tau$ is the pension contribution rate.

Covered labor earnings net of pension contributions and private savings returns are subject to a progressive income tax. Taxes due at period $t$ are denoted $T\left(a_{t}, w_{C, t}^{H}, w_{C, t}^{W}, d_{t}\right)$, and depend on the household's stock of private savings, received covered sector offers and decisions to accept them. Net borrowing and borrowing against pension savings is not allowed. Private savings earn the risk-free rate $r$. The balances on each spouse's pension account accrue interests stochastically and are augmented by the current period's contribution. Returns on the pension accounts are modeled as an iid process: $r_{B} \sim i i d N\left(r_{B}^{-}, \sigma_{B}^{2}\right) .{ }^{14}$.

\subsubsection{The Working Household's Problem}

The optimization problem faced by the household at working ages can be written recursively:

$$
\begin{aligned}
& V_{t}\left(a_{t},\left\{B_{t}^{i}\right\}_{i},\left\{E^{i}\right\}_{i},\left\{X_{j, t}^{i}\right\}_{i, j}, d_{t-1} ; c\right)= \\
& \quad \max _{c_{t}, d_{t}}\left\{u\left(c_{t}, d_{t}\right)+\beta E V_{t+1}\left(a_{t+1},\left\{B_{t+1}^{i}\right\}_{i},\left\{E^{i}\right\}_{i},\left\{X_{j, t+1}^{i}\right\}_{i, j}, d_{t-1} ; c\right)\right\}
\end{aligned}
$$

s.t.

$$
\begin{aligned}
& a_{t+1}=y_{t}+a_{t} \cdot(1+r)-c_{t}-T\left(a_{t}, w_{C, t}^{H}, w_{C, t}^{W}, d_{t}\right) \\
& a_{t+1} \geq 0 \\
& B_{t+1}^{i}=B_{t}^{i} \cdot\left(1+r_{B}\right)+\tau \cdot w_{C, t}^{i} \cdot d_{C, t}^{i}, i \in\{H, W\}
\end{aligned}
$$

\footnotetext{
${ }^{14}$ Allowing for serial correlation in the returns would require adding past returns as additional continuous state variables which would significantly complicate the numerical solution of the problem
} 


\subsubsection{Retirement}

At retirement, spouses stop working:

$$
d_{t}=(3,3) \text { for } t>t_{R}
$$

They receive as a lump sum the welfare or minmum pension benefits if they meet the eligibility criteria, and then withdraw all pension savings and pool them with their private savings:

$$
a_{t_{R}}=a_{t_{R}}+B_{t_{R}}^{H}+B_{t_{R}}^{W}+\text { Benefits }
$$

There is no uncertainty remaining at this point, and households run down their total accumulated private and pension savings by optimally saving and consuming until they die. Letting $a_{t}$ denote the total amount of savings at $t$, pensions included, the problem of the retired household becomes:

$$
\begin{aligned}
\forall t \in\left\{t_{R}, \ldots t_{D}\right\} V_{t}\left(a_{t}\right) & =\max _{a_{t+1}}\left\{u\left(c_{t},(3,3)\right)+\beta \cdot E V_{t+1}\left(a_{t+1}\right)\right\} \\
\text { where } c_{t} & =a_{t+1}-a_{t} \cdot(1+r) \\
a_{t} & \geq 0 \\
\text { and } V_{t_{D}+1}\left(a_{t_{D}+1}\right) & =0
\end{aligned}
$$

\subsection{Solution Method}

The problem of the retired household can be solved analytically. The details are presented in appendix A. For working periods, the model does not have an analytic solution. Instead it is numerically solved by backwards recursion.

The details of the solution procedure are the following. At age $t_{R}-1$, a household decides on consumption and labor sectors to maximize the weighted sum of current and future period 
utilities, denoted by $V_{t_{R}-1}\left(\overline{S_{t_{R}-1}},\left\{\epsilon_{j, t_{R}-1}^{i}\right\}\right)$, where the state space, $S_{t_{R}-1}$, is divided into a deterministic component containing the elements that are not random at the beginning of period $t_{R}-1, \overline{S_{t_{R}-1}}$, and a shock component containing the vector of random earnings shocks drawn at $t_{R}-1,\left\{\epsilon_{j, t_{R}-1}^{i}\right\}$.

For any given value of the deterministic and shock components of the state space, optimal consumption is obtained by comparing utility on a grid of possible consumption levels, for each of the nine possible choices of husbands' and wives' labor sectors. The labor decision and associated optimal consumption that maximizes total utility is chosen for that value of the state space. At any deterministic state point, the expected value of $V_{t_{R}-1}$ is obtained by Monte Carlo integration, that is, by taking draws from the shock vector distribution and averaging to obtain $E V_{t_{R}-1}\left(\overline{S_{t_{R}-1}}\right)$. This expectation is calculated at a subset of the deterministic state points and the function is approximated for all other state points by a polynomial regression following an approximation method developed by Keane and Wolpin (1994, 1997). I denote this function as $\operatorname{Emax}\left(t_{R}-1\right)$.

This procedure is repeated at age $t_{R}-2$. Using the recursive formulation of the value function, substituting the $\operatorname{Emax}\left(t_{R}-1\right)$ function for the future component, the optimal decision is computed. Monte Carlo integration over the shock vector at $t_{R}-2$ provides $E V_{t_{R}-2}\left(\overline{S_{t_{R}-2}}\right)$ for a given deterministic state point. A polynomial regression over a subset of the state points again provides an approximation to the function, denoted by $\operatorname{Emax}\left(t_{R}-2\right)$. Repeating the procedure back to the initial age provides the Emax polynomial approximation at each age. The set of $\operatorname{Emax}(t)$ functions fully describe the solution to the optimization problem.

\section{Data and Estimation}

\subsection{Description of the Dataset and Variables of Interest}

The model is estimated using individual and household earnings, labor sector choice and asset data from the Encuesta de Proteccion Social longitudinal survey (EPS) together with the linked administrative records of pension balances and contributions to retirement accounts, 
obtained from the Superintendencia de Administradoras de Fondos de Pension (SAFP) (the Chilean supervising agency for pension fund administrators). EPS is a new household survey, conducted in 2002 by the Microdata Center (Centro de Microdatos) of the Department of Economics of the Universidad de Chile. It was initially called HLLS and later renamed Encuesta de Proteccion Social (EPS). The questionnaire was designed specifically to study Chile's social protection public programs. ${ }^{15}$ In 2004 and 2006, two follow-up surveys were administered. The 2009 follow-up survey was administered in the course of 2009 and was not exploited in this study.

The 2006 survey contains information on a representative sample of 16443 individuals of age 15 or older. For the 14337 of them that are affiliated to the AFP pension system, the administrative records of all the transactions on their pension accounts are linked to the EPS survey.

The variables used in the estimation are: age, schooling level, schooling level of the spouse, number of years the respondent worked in the covered sector, number of years the respondent worked in the uncovered sector, labor sector choice, labor sector choice of the spouse, annual accepted earnings, individual pension wealth and private household wealth.

The schooling level variables were constructed as a discrete indicator taking values 4 (individuals with less than 8 years of schooling), 8 (individuals with 8 to 11 years of schooling), 12 (individuals with 12 to 15 years of schooling), and 16 (individuals with 16 years of schooling or more). The four categories are labeled No High School, High School drop-out, High School graduate and College graduate for simplicity thereafter.

Respondents were asked to report their spells of employment since their first job or since 1980, whichever happened last. Employment spells in salary jobs with a contract were coded as covered, while self-employed spells and salary jobs without a contract were classified as uncovered. ${ }^{16}$ From employment spells, a monthly indicator of employment status was

\footnotetext{
${ }^{15}$ Historia Laboral y Seguridad Social

${ }^{16}$ For self-employed workers, contributions to the system are optional rather than mandatory. About one out of six self-employed worker is actually covered (Arenas de Mesa et al. (2004)). This paper assesses the effect of the constraint imposed by mandatory savings on coverage, so that self-employed workers, who are not subject to that constraint are classified as uncovered.
} 
constructed. This monthly indicator was aggregated to an annual indicator in the following way. A respondent with no working months during the year is $\operatorname{Home}\left(d_{t}^{3}=1\right)$. A respondent with a majority of months in covered jobs is Covered $\left(d_{t}^{2}=1\right)$, and a respondent with a majority of uncovered jobs is Uncovered $\left(d_{t}^{2}=1\right)$. The annual indicator was then summed from the year in which the respondent turned 16 to the each year to obtain the number of years in each labor choice. Regarding the spouse's labor sector choice, it was constructed in the same way for the years the survey was administered (2002-2004-2006). Monthly labor earnings were reported for each employment spell starting in 2002. They were summed over each year to obtain annual accepted earning.

Household wealth was reported in the 2004 and 2006 surveys and is composed of main housing, real estate, cars, savings, equipment, businesses and debts. The pension wealth of the EPS respondent was obtained from the pension account administrative records in the following way. Every time a pension contribution is made (i.e. every month worked in a covered job), the transaction records the balance on the account at the time of the contribution. For month in which the respondent didn't work in a covered job (i.e. was at home or working in an uncovered job), the balance is computed using the last available balance, the returns obtained by the corresponding pension fund, and the commissions or fees charged by the pension fund manager. All variables except for pension balances are available for both spouses in years 2004 and 2006. Pension balances are available for the survey's interviewee from 1980 to 2005, but not for his or her spouse. Labor decisions of the survey's interviewee are reported from 1980 to 2006 and his or her earnings from 2002 to 2006.

The sample used in the analysis is restricted as follows. First, I keep 8193 married and cohabitating couples that have been together at least from 2002 to 2006. Of those, I exclude 822 who kept their affiliation to the old pension system, which is not modeled in this paper. Couples formed after the husband turned 25 were also dropped to avoid having households with significant asset accumulation and work experience prior to marriage, since initial conditions are kept fixed in the policy experiments. This leaves 4154 couples. The 
final sample consists of the 2097 households that were formed after 1980, and were subject only to the post-1980 privatized pension system.

The data includes individuals that were born between 1965 and 1981. The older cohorts are observed from the age of 25 to the age of 51, while the younger cohorts are observed only one or two years (see table 16).

Table 15 presents summary statistics for the sample. Median private savings at age 35 in the sample are about 4.8 million pesos, or about 8000 dollars. This corresponds roughly to twice the median earnings in the covered sector. In comparison, median pension savings at the same age are about 2.3 million pesos for males and 0.3 million pesos for females. The relative importance of pension savings increases over the lifecycle. The fact that the median female pension savings is much lower and is decreasing with age is due to low female labor force participation, particularly for older cohorts.

The median male worker earns 2.4 million pesos annually when working in the covered sector, versus 1.7 million pesos in the uncovered sector. This difference is in part due to the different levels of schooling in the two sectors. The sample is divided into 4 schooling levels: less than High School, some High School, High School graduates and College graduates. Lower schooling levels are over-represented in the uncovered sector: the fraction of males with no High School education is $24 \%$ among uncovered workers versus $15 \%$ in the total sample. Table 15 also reports the joint sector choices made by households in the sample: about $37 \%$ households have two working members, $59 \%$ have one, and $4 \%$ have none. $24 \%$ of couples have two spouses in the same sector: $18 \%$ in the covered sector, and $8 \%$ in the uncovered sector. A sizeable fraction of the sample, $13 \%$ is comprised of couples that are split between the two sectors, about $1 / 3$ of all two-income households.

Looking at the fraction of working years spent in the covered sector, it is possible to distinguish three types of workers. $20 \%$ of males and $25 \%$ of females work less than $25 \%$ of the time in the covered sector. That is, they almost only work in uncovered jobs. Similarly, $60 \%$ of males and $58 \%$ of females work almost exclusively in covered jobs. Finally, a large fraction of the sample (20\% of males and $17 \%$ of females) switches in and out of covered 
jobs.

\subsection{Estimation of the Model's Parameters}

I estimate the model using a Method of Simulated Moments (MSM). ${ }^{17}$ I use the approximated age-dependent value functions, conditional on the state variables, to simulate moments of the wealth, sector-specific earning and labor choice distributions. The moments are generated for any given set of parameters by simulating the behavior of 5 "clones" of the 2, 097 couples in the estimation sample. The estimation procedure then minimizes the distance between the simulated moments and corresponding data moments. The weights are the inverses of the estimated variances of the moments.

\subsubsection{Data Moments Used in the Estimation}

The groups of data moments used for the estimation are listed below with the number of moments in parentheses:

- Joint Labor Sector Choice:

1. The proportion of households choosing each of the nine joint occupations by age group (9x6 moments).

2. The proportion of households choosing each of the nine joint occupations by schooling level of the husband (9x4 moments).

3. The proportion of households choosing each of the nine joint occupations by schooling level of the wife (9x4 moments).

4. The proportion of two-income households by age group (6 moments).

5. The proportion of two-income households by schooling level of the husband (4 moments).

\footnotetext{
${ }^{17}$ This method more easily accommodates missing state variables than does simulated maximum likelihood, which would require integrating over possible values of missing state variables.
} 
6. The proportion of two-income households by schooling level of the wife (4 moments).

7. The proportion of one-income households by age group (6 moments).

8. The proportion of one-income households by schooling level of the husband (4 moments).

9. The proportion of one-income households by schooling level of the wife (4 moments).

10. The proportion of husbands choosing each of the three alternatives by schooling level(3x4 moments).

11. The proportion of husbands choosing each of the three alternatives by age group (3x6 moments).

12. The proportion of wives choosing each of the three alternatives by schooling level(3x4 moments).

13. The proportion of wives choosing each of the three alternatives by age group $(3 \times 6$ moments).

14. The proportion of husbands choosing each of the three alternatives by 5-year tranches of covered experience (3x6 moments).

15. The proportion of husbands choosing each of the three alternatives by 5-year tranches of uncovered experience (3x6 moments).

16. The proportion of wives choosing each of the three alternatives by 5 -year tranches of covered experience (3x6 moments).

17. The proportion of wives choosing each of the three alternatives by 5 -year tranches uncovered experience (3x6 moments).

18. The proportion of husbands choosing each of the three alternatives by agegroup and birth cohort $((6+6+5+4+3) \times 3$ moments $) .{ }^{18}$

\footnotetext{
${ }^{18}$ Cohorts 1 and 2 are observed over 6 age groups, cohort 3 over 5 age groups etc.
} 
19. The proportion of wives choosing each of the three alternatives by agegroup and birth cohort $((6+6+5+4+3) \times 3$ moments $) .{ }^{19}$

- Wealth:

1. The mean private savings level by age and schooling level of the husband $(4 \mathrm{x} 6$ moments).

2. The mean private savings level by age and schooling level of the wife $4 \times 6$ moments).

3. The variance of private savings by age (6 moments).

4. The variance of private savings by schooling level of the husband (4 moments).

5. The variance of private savings by schooling level of the wife (4 moments).

6. The mean pension savings level by sex, age and schooling level (2x4x6 moments).

7. The variance of pension savings by sex and age (2x6 moments).

8. The variance of pension savings by sex and schooling level (2x4 moments).

9. Fraction with no private savings by age group (5 moments).

10. Fraction with private savings between 0 and 6 million pesos by age group (5 moments).

11. Fraction with private savings over 6 million pesos by age group (5 moments).

12. The mean private savings level by age and current sector of the husband $(2 \mathrm{x} 6$ moments).

13. The mean private savings level by age and current sector of the wife $(2 \mathrm{x} 6$ moments).

14. The mean pension savings level by agegroup and birth cohort $(6+5+4+3+2$ moments).

\footnotetext{
${ }^{19}$ The labor force participation decisions of cohorts 1 and 2 are observed over 6 age groups, cohort 3 over 5 age groups etc.
} 


\section{- Earnings:}

1. The mean annual log-earnings by sex, age and sector (2x6x2 moments).

2. The variance of the annual log-earnings by sex, age and sector (2x6x2 moments).

3. The mean annual log-earnings by sex, age and schooling level (2x4x2 moments).

4. The variance of the annual log-earnings by sex, age and schooling level $(2 \times 4 \times 2$ moments).

5. The mean annual log-earnings by sex, sector and experience (2x2x6 moments).

6. The mean first-difference in annual log-earnings by current and 1-year lagged sector and by $\operatorname{sex}(2 \times 2 \times 2$ moments $)$.

7. The mean first difference in annual log-earnings by age, current sector and by sex (6x2x2 moments).

- Career Transitions:

1. 2-period joint transitions of number of working spouses in the household (9 moments).

2. 1-period transitions between the three employment status by age group and sex (3x3x6x2 moments).

3. mean years in each sector by age group and sex (3x6x2 moments).

4. Fraction of years in covered sector under age 35 by sex ( $5 \times 2$ moments).

5. Fraction of years in covered sector over age 35 by sex ( $5 \times 2$ moments).

6. Fraction of years at home under age 35 by sex ( $5 \times 2$ moments).

7. Fraction of years at home over age 35 by sex ( $5 \times 2$ moments).

The total number of moments is $M=953$, the number of parameter to be estimated is $K=59$. 


\subsubsection{Standard Errors}

Let's denote $x_{i}^{m}$ the contribution of observation $i$ to moment $m, i \in 1 . . N, m \in 1 \ldots M$. Denote $S^{m}$ the set, and $N^{m}$ the number, of observations that contribute to moment $m$. Finally, the theoretical model predicts a value for each moment, denoted $\mu^{m}(\theta)$, where $\theta=\left[\theta_{1}, \ldots \theta_{K}\right]$ is the vector of estimated parameters.

The Method of Simulated Moments estimator is defined as:

$$
\hat{\theta}_{N}=\underset{\theta \in \Theta}{\arg \max }\left[\frac{1}{N^{m}} \sum_{i \in S^{m}}\left(x_{i}^{m}-\mu^{m}(\theta)\right)\right]_{m=1 \ldots M}^{\prime} W^{-1}\left[\frac{1}{N^{m}} \sum_{i \in S^{m}}\left(x_{i}^{m}-\mu^{m}(\theta)\right)\right]_{m=1 \ldots M} .
$$

The inverse of the weighting matrix $W$ is an $M$ by $M$ diagonal matrix with the $m^{\text {th }}$ diagonal elements equal to the sample variance of $x_{i}^{m}$.

Given the moments chosen above, not all observations contribute to all moments. In order to derive the asymptotic properties of the estimator it is convenient to note that:

$$
\begin{aligned}
& \hat{\theta}_{N}= \\
& \underset{\theta \in \Theta}{\arg \max }\left[\frac{1}{N} \sum_{i \in S}\left(x_{i}^{m}-\mu^{m}(\theta)\right) \cdot D_{i}^{m} \cdot \frac{1}{N^{m}}\right]^{\prime} W^{-1}\left[\frac{1}{N} \sum_{i \in S}\left(x_{i}^{m}-\mu^{m}(\theta)\right) \cdot D_{i}^{m} \cdot \frac{1}{N^{m}}\right]
\end{aligned}
$$

where $D_{i}^{m}$ is a dummy that is equal to one if observation $i$ contributes to moment $m$, and $S$ is the union of all $S^{m} \mathrm{~s}$.

Taking first order conditions with respect to $\theta$ yields:

$$
\left[\left.\frac{1}{N} \frac{\delta \mu^{m}}{\delta \theta}\right|_{\hat{\theta}_{N}}\right]^{\prime} W^{-1}\left[\frac{1}{N} \sum_{i \in S}\left(x_{i}^{m}-\mu^{m}(\theta)\right) \cdot D_{i}^{m} \cdot \frac{1}{N^{m}}\right]=0
$$

A Taylor expansion of $\mu^{m}$ around the true parameter vector $\theta_{0}$ yields:

$$
\mu^{m}\left(\hat{\theta}_{N}\right)=\mu^{m}\left(\theta_{0}\right)+\left.\frac{\delta \mu^{m}}{\delta \theta}\right|_{\theta *} \cdot\left(\hat{\theta}_{N}-\theta_{0}\right)
$$


for some $\theta *$ between $\hat{\theta}_{N}$ and $\theta_{0}$. Combining (1) and (2), we obtain after rearranging:

$$
\begin{aligned}
& \sqrt{N}\left(\hat{\theta}_{N}-\theta_{0}\right)= \\
& {\left[\left[\left.\frac{\delta \mu^{m}}{\delta \theta}\right|_{\hat{\theta}_{N}}\right]^{\prime} W^{-1}\left[\left.\frac{\delta \mu^{m}}{\delta \theta}\right|_{\hat{\theta} *}\right]\right]^{-1}\left[\left.\frac{\delta \mu^{m}}{\delta \theta}\right|_{\hat{\theta}_{N}}\right]^{\prime} W^{-1}\left[\frac{1}{\sqrt{N}} \sum_{i \in S}\left(x_{i}^{m}-\mu^{m}\left(\theta_{0}\right)\right) \cdot D_{i}^{m} \cdot \frac{N}{N^{m}}\right] .}
\end{aligned}
$$

A central limit theorem can be applied after redefining

$$
\tilde{x}_{i}^{m} \equiv x_{i}^{m} \cdot D_{i}^{m} \cdot\left(\frac{N}{N^{m}}\right)
$$

and

$$
\tilde{\mu}_{i}^{m}\left(\theta_{0}\right) \equiv \mu_{i}^{m}\left(\theta_{0}\right) \cdot D_{i}^{m} \cdot\left(\frac{N}{N^{m}}\right) .
$$

The estimator's asymptotic variance-covariance matrix is given by:

$$
A s y . V a r\left(\hat{\theta}_{N}\right)=\left(D_{0}^{\prime} W^{-1} D_{0}\right)^{-1} D_{0}^{\prime} W^{-1} W_{0}^{-1} W^{-1} D_{0}\left(D_{0}^{\prime} W^{-1} D_{0}\right)^{-1 \prime}
$$

where $D_{0}=E\left[\left.\frac{\delta \mu^{m}}{\delta \theta}\right|_{\theta_{0}}\right], W_{0}=E\left(\left[\tilde{x}_{i}^{m}-\tilde{\mu}_{i}^{m}\left(\theta_{0}\right)\right]^{\prime}\left[\tilde{x}_{j}^{m}-\tilde{\mu}_{j}^{m}\left(\theta_{0}\right)\right]\right)$.

In computing the standard errors, $D_{0}$ is approximated by the numerical derivatives of the model's moments at the estimated vector of parameters, $W_{0}$ is approximated by the

sample variance-covariance of $\left[\tilde{x}_{j}^{m}-\tilde{\mu}_{j}^{m}\left(\theta_{0}\right)\right]$, and the standard errors are corrected for the variance resulting from replacing the true model-implied moments by simulated moments. The standard errors are reported below the parameter estimates in tables 1, 2, 3 and 4 .

\subsection{Estimation Results}

\subsubsection{Parameter Estimates}

Tables 1, 2, 3 and 4 report parameter estimates with the standard errors in parentheses. The discount rate is estimated at 0.067 (for a discount factor of 0.937 ). This is slightly higher than what is usually found in models estimated or calibrated on American data (usually under 
0.05). However, this is to be compared to the higher interest rates experienced by Chile over the estimation period. In fact, the ratio $\frac{1+r}{1+\rho}$, which drives asset accumulation, is close to what is found elsewhere in the literature at 1.0127 (compared to 1.0106 in Gourinchas and Parker (2002), for example). The elasticity of intertemporal substitution is estimated at 1.559 , which is within the (wide) range of estimates found in the literature. For example Van der Klaauw and Wolpin (2008) find estimates of 1.59 and 1.68, and Gourinchas and Parker (2002) obtain 1.397.

Some parameters from the earnings offer function are worth highlighting. First, experience transferability is estimated to be high, at 0.97 . This would imply that sector-specific human capital accumulation is not an important factor in keeping workers away from the covered sector. It must be noted that the standard errors on this parameter are relatively high at 0.111 . On the other hand, the probability of receiving a covered offer is significantly below one, but only for the lowest schooling level. Male workers with no High School and one year of experience in the covered sector have almost $5 \%$ of chances of not receiving a covered offer every period (see figure 3). The importance of this is magnified by the fact that workers anticipate that if they accept a covered offer they might have to switch sectors and pay the corresponding non-pecuniary costs sometime in the future. This probability is lower as covered experience is accumulated, but only to an extent. No High School male workers with 15 years of covered experience still face about $3 \%$ chances of not receiving a covered offer (see figure 4). The probability of receiving a covered offer increases with the schooling level, and is, for example, 0.99 for High School dropouts with 15 years of experience. In other words, only low schooling workers find themselves sometimes exogenously excluded from the covered sector. Also, the returns to education are estimated to be higher in the uncovered sector than in the covered sector (3.4\% higher for men and $1.8 \%$ higher for women). This implies that the earnings gap between sectors is higher for low schooling levels. Overall, these estimates suggest that the segmented or residual model of the uncovered sector is relevant for workers with low levels of schooling, possibly because minimum wage regulations induce an excess supply of labor in the covered sector. For workers with some schooling, however, 
even High School dropouts, the estimates are consistent with an uncovered sector that offers real "career" opportunities, with human capital accumulation that is portable to jobs in the covered sector.

\subsubsection{Model Fit}

We next examine evidence on how the model fits the data within sample. Tables 5 and 6 provide evidence on the within-sample fit of the model in the savings accumulation dimension. Tables 7, 8, 9, 10, 11 and 12 show aspects of the labor sector choices. Tables 13 and 14 summarize earnings.

First, the model is able to generate the overall dispersion of the private savings, pension savings and earnings in the sample, as seen in tables 5 and 6 . In addition, the education and age patterns of mean savings and earnings are well captured overall. Two aspects of the fit could be improved. First, the model tends to underpredict pension savings accumulation at older ages for college graduates. Looking at earnings, the mean for that schooling level are also lower in the model simulations than in the data. In fact, college graduate earnings exhibits a fat right tail of high earners that the model is not well equipped to capture. The fact that these high earnings are persistent over time explains that this right tail in the earnings distribution also translates into a fat right tail in the pension savings distribution, which is responsible for the underestimation of college graduate pension savings. The pension savings accumulated by these high earning individuals will tend to pull the mean up at older ages. $^{20}$ The second aspect is the low mean earnings of younger males and of females in the uncovered sector. This comes from workers who are only partially employed during the year, a situation that is common in the informal sector at younger ages. Since I make the simplifying assumption not to model the intensive margin of the labor supply decision, the model is not well equipped to capture that fact.

Second, the joint labor force participation of couples in the nine possible pairs of employment choices (table 7) is also well captured. So are the individual choices of husbands

\footnotetext{
${ }^{20} \mathrm{~A}$ possible remedy would be to introduce unobserved heterogeneity in the earnings offer, effectively allowing for persistently high earnings and pension savings accumulation for a fraction of the sample.
} 
and wives, summarized by age (table 8) and schooling level (table 9). For example, the model reproduces the high percentage of women with no High School education who stay home $(14.8 \%$ versus $13.4 \%$ in the data) and the much lower percentage for college graduates ( $27.4 \%$ versus $25.0 \%$ in the data).

Third, it is important that the model captures how workers switch or stay in the same sector over their careers as seen in table 10. The model reproduces the bimodal distribution of time spent in the covered sector at different ages and for the two genders. For example, $18.8 \%$ of men under 35 have worked than $25 \%$ of the time in covered jobs $(18.8 \%$ in the data), while $58.7 \%$ have worked more than $75 \%$ of the time in covered jobs $(58.5 \%$ in the data). Tables 11 and 12 show the individual transition matrices for 45-50 year-old men and women and for their younger counterparts (25-30). In particular, the persistence in sector choices is adequately captured for both genders and age groups.

\section{$5 \quad$ Policy Experiments}

Having estimated the structural parameters governing preferences, earnings offers and labor market segmentation, I use the model to perform policy experiments that assess the effect of the rules of the pension system on asset accumulation, pension system coverage, labor force participation, and the fiscal cost of the pension system's safety net. In particular, I solve the model under the alternative rules, and simulate the decisions of the sampled households from the first decision period (start of marriage/cohabitation) rather than imposing the new rules form a given year on, in order to evaluate the long-term effects of the alternative rules. ${ }^{21}$

Given that they are primitives of the model, the estimated preference parameters can be taken as invariant to policy changes. The prices in the labor and capital markets, however, might be subject to equilibrium adjustments when pension rules are changed. Equilibrium effects could operate through three channels. First, asset returns might adjust to an increase

\footnotetext{
${ }^{21}$ Note that the experiments are not tax-neutral: the additional cost to the government are not translated into higher taxes. Results for same policy changes modeled as an unanticipated and tax-neutral event will be the object of future work.
} 
or a reduction in household savings, thus attenuating the behavioral response to the policy change. It seems reasonable to assume, however, that Chile is a small open economy and that asset returns are invariant to the policy experiment. Second, the adjustment in the relative wages of the covered and uncovered sector can be expected to reduce the extent to which workers switch sectors in response to changes in the rules of the system. Similarly, if new rules cause workers to reduce their labor force participation, wages might go up in equilibrium and limit the magnitude of the response. The wage equilibrium effects are outside the scope of my paper, so the estimates of the employment responses to the policy experiments presented here should be taken as upper bounds on the equilibrium response.

In reporting the effects of the policy experiment, I use 2004 as the baseline year since the EPS sample was chosen to be representative of the Chilean population in that year. As previously noted, there are several sample selection criteria and the results here apply only to the sample analyzed.

\subsection{Alternative Contribution Rules}

I first study changes in the mandatory pension contribution rate, which is currently set at $10 \%$. The goal of the experiment is to understand the strength of the incentives for workers to switch to the uncovered sector in order to avoid paying pension contributions. In other words, the idea is to determine to what extent low pension coverage might be related to the level of illiquid pension contribution. In addition, from a public finance point of view, it is interesting to see whether higher pension contributions result in higher total savings and how the cost of the pension system is affected.

\subsubsection{Findings}

Table 17 summarizes the outcomes of interest under counterfactual contribution rates ranging from $5 \%$ to $20 \%$. Realized pension returns after 2009 are assumed to be $5.98 \%$, which corresponds to the weighted average return on Chile's pension funds from 2002 to $2009^{22}$.

\footnotetext{
${ }^{22}$ The effect of different returns assumptions are explored in the second policy experiment.
} 
Statistics like mean savings and the fraction of husbands and wives in each occupation are reported for the year 2004. I also project the decisions of the households in the sample until retirement to obtain age profiles of mean private and pension savings (pooling together all birth cohorts in the sample), eligibility for minimum pension benefits and government liabilities.

The exercise essentially measures the elasticity of pension coverage to the level of pension contributions implied by the model. Changes in the mandatory contribution rate can affect pension coverage and labor force participation by reducing the value of covered earnings offers. The predicted coverage rate in 2004 shows that households significantly adjust their labor force participation in response to a change in mandatory savings. Increasing the contribution rate from 10 to 15 percent decreases the coverage rate by 1.1 percentage points or $5.9 \%$ for husbands and $16.5 \%$ for wives. In addition, female labor force participation decreases by $3.2 \%$. However, the coverage rate by itself provides an incomplete picture of participation in the pension system. It does not capture whether the same workers participate continuously over their lifetime while others never do or whether most workers switch in and out of covered jobs to some extent. To see this, I consider the density of contributions, which is the number of years in which contributions where made over the number of workingage years. $^{23}$ Table 18 shows the distribution of contribution densities at age 64 under a contribution rate of $10 \%$ and $15 \%$. As expected, contribution densities are lower when the contribution rate is higher. However, different parts of the distribution are affected by changes in the contribution rate for men and women. Women who reduce their participation in the covered sector are those with otherwise low contribution densities. The fraction of women with more than $75 \%$ of contributions remains virtually unchanged. In other words, a higher contribution rate discourages sporadic participation in the covered sector. In contrast, the whole contribution density distribution for male shifts to the left, exhibiting more workers with only uncovered experience and fewer with only covered experience.

In addition to impacting coverage, the contribution rate could be a tool to increase

\footnotetext{
${ }^{23} \mathrm{I}$ define working ages as ranging between 16 and 64 .
} 
aggregate savings by effectively imposing a lower bound on a household's overall saving rate. However, the magnitude of that effect depends on the extent to which households can make countervailing adjustments to their private savings. The effect of the contribution rate on asset accumulation is captured by several statistics. First, I report the average private, pension and total savings for the sample in 2004 in the different scenarios. The results show that total savings respond strongly to an increase in the contribution rate: increasing the contribution rate from 10 to 15 percent increases average total savings by $13.4 \%$, from 10.8 to 12.2 million pesos. This effect can be decomposed into an increase in pension savings $(+1.7$ million pesos for males and +0.3 million pesos for females) partially offset by a decrease in private savings (-0.6 million pesos).

The contribution rate also affects the cost of the state-provided safety net. First, if high contributions reduce participation in the covered sector, fewer workers will reach the number of years of contributions requirement to obtain the minimum pension. Second, conditional on being eligible, workers subject to a higher contribution rate requirement are less likely to have a pension below the guaranteed minimum. To assess the impact of the contribution rate on government liabilities, I determine for each individual in the sample whether they qualify for either the minimum pension or the welfare pension and compute the present value of predicted benefits payments. I discount the payments by the risk free rate and average over the total number of individuals in the sample. I project that less than $2 \%$ of males and $5 \%$ of females will qualify for the minimum pension. This results from the level of the minimum pension level (about $3 / 4$ of the minimum wage), the number of years of contributions required to qualify and the returns achieved by the system. Conditional on reaching the 20 years of contribution, few workers will accumulate less than the minimum pension level. As a consequence, the projected liability of workers in the sample remains limited at 655000 pesos per capita. That is, if the government wanted to pay off in 2004 all future benefits to workers in the sample, it would have to pay the equivalent of 6 months worth of the minimum wage to each of them. Multiplied by the total Chilean population 
this sum would represent $11 \%$ of GDP. ${ }^{24}$

\subsection{Ex-ante Evaluation of the 2008 Reform of the Safety Net}

The second policy experiment studies the effect of the 2008 reform of the safety net that was described in the introduction. The objectives of the reform were to protect workers with few pension contributions against old age poverty while increasing coverage by improving incentives to participate in the system. The model considers two channels by which retirement transfers can affect pension coverage. First, benefits can reduce labor force participation through an income effect. Second, the safety net might create a implicit marginal tax rate on additional pension contributions if they render the worker ineligible or reduce his claims to benefits.

I consider the question of whether the new system will improve or reduce pension coverage, and compare the predicted liabilities it will generate with that generated by the pre-2008 system's. My approach simulates the sample's lifetime decisions under the two pension system designs and compare outcomes. This exercise requires making an assumption on the realized rate of return achieved by pension funds. In the simulations, I use the historical realized rate of return from 1981 to 2009, and also consider three alternative scenarios. In the first scenario, post-2009 returns are fixed at 9.94\%, which is the mean return on the years spanned by my data (1981-2006). In the second scenario I use the mean return from 2002 to 2009, which includes large negative returns corresponding to the 2008 financial crisis (The Chilean pension funds lost about $20 \%$ of their value in 2008), for an average of $5.98 \% .{ }^{25}$ Finally I consider a low return scenario, in which pension accounts accrue $2.99 \%$, or half the returns in the second scenario.

\footnotetext{
${ }^{24}$ See Holzmann et al. (2004) for a discussion of implicit pension debt calculations

${ }^{25}$ Before 2000, each pension fund managed a unique portfolio. I use the average of all the funds' returns weighted by their value at the end of each year. In 2000 and 2002, pension funds were required to managed additional portfolios with different risk-return profiles. By default most accounts were attributed to the medium risk portfolio or "fondo C", whose returns I use in calculating returns post 2000.
} 


\subsubsection{Findings}

The results of the simulations are presented in table 19. I list the same outcomes as in the alternative contribution rate policy experiment, namely the fraction of husbands and wives in each sector in 2004, the fraction with contribution densities below $75 \%$ at retirement, mean private and pension savings in 2004 and by age until retirement, the fraction of the sample that is eligible for retirement transfers and the present value of those transfers, per capita, in 2004.

If we look at the coverage rates in the sample in 2004, the reform has almost no effect on males and a small negative effect on females $(-1.9 \%)$. However, the sample only contains the relatively young cohorts that started working under the new system, after 1980. As a result, the 2004 coverage rate does not capture the effects of the reform at older ages. In tables 20 and 21, I reproduce the projected sector choices by age groups. Although decisions at younger ages remain largely unaffected, the reform has a significant effect as retirement nears. For example the fraction of 60-64 year-old males who work in the covered sector decreases by $4.8 \%$ while females show a similar effect that starts earlier in the lifecycle and increases progressively with age.

The effect on uncovered sector participation differs in sign for males and females. Under the reformed system, females are less likely to work in either sector, which is consistent with an income effect on the demand for the home sector. However, males increase their participation in the uncovered sector as a result of the reform, which cannot be explained by an income effect. A closer look at the change in marginal tax rates provides a explanation. Although workers who would have qualified for either the welfare or the minimum pension in the old system see their implicit marginal tax rate decrease, and their incentives to work in covered jobs increase, the reverse is true of workers who become eligible under the 2008 reform. Those would see their marginal tax rate increase instead of decrease. Table 19 shows that the fraction eligible for any kind of retirement income transfer increases by 16.6 and 13.7 percentage points for husbands and wives respectively under the reform. This implies that the fraction of workers for whom the marginal tax rate increased is higher than that of 
workers for whom it decreased, which explains the shift towards the uncovered sector.

The expansion of the number of beneficiaries also implies an increase in the fiscal cost of the safety net. Table 19 reports predicted eligibility and fiscal liabilities for the old welfare pension, the old guaranteed minimum pension and the new welfare pension. Under the baseline scenario, with returns on pension accounts of $5.98 \%$, the present value of liabilities in the old system is estimated at 655,300 pesos per capita, versus 4,311,260 for the new system, which is 6.5 times higher. Multiplied by the Chilean population, these numbers correspond to $10.8 \%$ and $71.7 \%$ of the country's GDP in 2004. This large difference is due to the fact that only $1.5 \%$ of husbands and $4.4 \%$ of wives would have qualified for the guaranteed minimum pension, and another 3.6\% of households would have received the lower welfare pension, according the model's projections. By contrast, $21.7 \%$ of households are projected to receive benefits under the old system, and benefits will be on average higher than in the old system.

Predictions under alternative levels of realized returns show that the cost of the old safety net is very sensitive to pension returns and increases substantially when pension returns are low. Assuming returns of 2.99\%, the percent eligible for the old minimum pension goes up to $10.8 \%$ for males and $7.4 \%$, and the cost of the old safety net is multiplied by 2.5 , at $1,611,320$ pesos per capita (eq. to $26.6 \%$ of GDP). In comparison, the fiscal cost of the new system is also sensitive to returns, but the cost only increases by $50 \%$.

\section{Conclusion}

The existence of a large uncovered labor market, in which it is difficult to mandate participation to pension schemes, poses formidable challenges for designing pension systems in developing countries. In many of them, the fraction of workers who contribute to the existing pension scheme is low. In this context, choosing how much workers should contribute could affect participation, pension savings accumulation and ultimately the cost for the State to 
provide a safety-net in the form of retirement income subsidies. Conversely, generous eligibility requirements and benefits for such a safety-net could also crowd-out individual pension and private savings, further increasing the fiscal cost of the system. This study explores these mechanisms by specifying and estimating a dynamic model of employment and savings decisions for a sample of Chilean couples under a privatized pension system. The model explicitly incorporates the main features of the pioneering Chilean pension system and allows households to adjust to pension regulation through a private saving decision and by varying the labor force participation decision of each spouse. In addition, the model accounts for the existence of a large uncovered labor market, in which household members can work without being subject to pension contributions.

In particular, this study attempts to determine to what extent pension rules themselves can be held responsible for the problem of low participation to the pension system. Specifically, are workers avoiding pension contributions? Do social pensions crowd-out contributions? Or are workers being rationed out of covered jobs due to labor market segmentation? In addition, it tries to assess what the effects of actual or potential policies that aim to increase income in retirement will be. This include increasing the contribution rate, and expand social pensions in the way Chile did it in 2008.

I find that Chilean data used in estimation are broadly consistent with a competitive, as opposed to a segmented, uncovered labor market sector. Labor market segmentation accounts for $13 \%$ of uncovered work overall (up to $22 \%$ for workers with no High School education).

I also predict that participation in jobs covered by the pension system are sensitive to the rules of the pension system. A higher contribution rate reduces participation in jobs that are covered by the pension system at a rate of 1 percentage point of coverage per additional percentage point of contribution. Private and pension savings are found to be only partial substitutes. Higher contributions would be partially offset by a reduction in private savings: the decrease in private savings equals roughly $25 \%$ of the increase pension savings. This implies that increasing contributions from $10 \%$ to $15 \%$ would increase total savings by $14 \%$. 
The model is used to ex-ante evaluate the 2008 expansion of Chile's safety net. I find that the reform operates a large redistribution towards workers with low pension saving accumulation and will result in a large increase in fiscal liabilities linked to welfare pensions (about 6 times the cost of the previous safety net). In addition, reduced labor force participation at older ages should be expected (husbands $-5 \%$, wives -23\%) despite a design that tries encourage participation.

Future research would be needed to externally validate the model using the next, postreform round of the survey. In addition, it would be interesting to conduct revenue-neutral policy experiments, that take into account the impact of the income tax increases required to finance the new safety net. The effects of a number of other possible policies could be investigated: alternative taper rates, matching of contributions by the State, and agedependent contribution rates.

\section{References}

Arenas de Mesa, A., J. R. Behrman, And D. Bravo (2004): "Characteristics of and Determinants of the Density of Contributions in a Private Social Security System," Working paper, University of Michigan, Retirement Research Center.

Blau, D. And D. Gilleskie (2006): "Health insurance and retirement of married couples," Journal of Applied Econometrics, 21, 935-953.

Corsetti, G. And K. Schmidt-Hebbel (1997): "Public pension plans in international perspective," in The Economics of Pensions, Cambridge University Press.

Dammon, R., C. Spatt, And H. Zhang (2004): "Optimal asset location and allocation with taxable and tax-deferred investing," The Journal of Finance, 59, 999-1037.

Dickens, W. And K. LAng (1985): "A test of dual labor market theory," The American Economic Review, 75, 792-805. 
Engen, E., W. Gale, And J. Scholz (1996): "The illusory effects of saving incentives on saving," The Journal of Economic Perspectives, 113-138.

Engen, E. M., W. G. Gale, And J. K. Scholz (1994): "Do Savings incentives work?" Brookings Papers on Economic activity, 1994, 85-180.

Gale, W. And J. Scholz (1994): "IRAs and household saving," The American Economic Review, 84, 1233-1260.

Gindling, T. (1991): "Labor market segmentation and the determination of wages in the public, private-formal, and informal sectors in San Jose, Costa Rica," Economic Development and Cultural Change, 39, 585-605.

Gomes, F., A. Michaelides, And V. Polkovnichenko (2005): Wealth accumulation and portfolio choice with taxable and tax-deferred accounts, Centre for Economic Policy Research.

Gong, X. And A. Van Soest (2002): "Wage differentials and mobility in the urban labour market: a panel data analysis for Mexico," Labour Economics, 9, 513-529.

Gong, X., A. Van Soest, and E. Villagomez (2004): "Mobility in the urban labor market: a panel data analysis for Mexico," Economic Development and Cultural Change, $53,1-36$.

Gourinchas, P.-O. And J. A. Parker (2002): "Consumption over the Life Cycle," Econometrica, 70, 47-89.

Gustman, A. And T. Steinmeier (2000): "Retirement in dual-career families: a structural model," Journal of Labor Economics, 18, 503-545.

- (2002): "Social Security, pensions and retirement behaviour within the family," Journal of Applied Econometrics, 19, 723-737. 
Heckman, J. and V. Hotz (1986): "An Investigation of the Labor Market Earnings of Panamanian Males Evaluating the Sources of Inequality," Journal of Human Resources, $21,507-542$.

Holzmann, R., R. Palacios, and A. Zviniene (2004): "Implicit pension debt: Issues, measurement and scope in international perspective," World Bank Social Protection Discussion Paper, 403.

Hubbard, G., J. Skinner, and S. P. Zeldes (1995): "Precautionary Savings and Social Insurance," The Journal of Political Economy, 103, 360-399.

Jimenez-Martin, S. And A. Sanchez-Martin (2007): "An evaluation of the life cycle effects of minimum pensions on retirement behavior," Journal of Applied Econometrics, 22, 923-950.

Magnac, T. (1991): "Segmented or competitive labor markets," Econometrica: journal of the Econometric Society, 59, 165-187.

MALONEY, W. (1999): "Does informality imply segmentation in urban labor markets? Evidence from sectoral transitions in Mexico," The World Bank Economic Review, 13, $275-302$.

McFadden, D. (1989): "A method of simulated moments for estimation of discrete response models without numerical integration," Econometrica: Journal of the Econometric Society, 995-1026.

Piggot, J., D. Robalino, and S. Jimenez-Martin (2009): "Incentive Effects of Retirement Income Transfers," in Closing the Coverage Gap, The World Bank.

Robalino, D., E. Zylberstajn, H. Zylberstajn, and L. Afonso (2008): "An ExAnte Evaluation of the Impact of Social Insurance Policies on Labor Supply in Brazil: The Case for Explicit over Implicit Redistribution," . 
Sanchez-Martin, A. R. (2008): "Endogenous retirement and public pension system reform in Spain," Working Papers, Universidad Pablo de Olavide, Department of Economics.

VAldÉS-Prieto, S. (2008): "A theory of contribution density and implications for pension design," Pensions Primer. World Bank, Washington, DC.

Van der Klaauw, W. and K. Wolpin (2008): "Social Security and the Retirement and Savings Behavior of Low-income Households," Journal of Econometrics, 145, 21-42.

Velez-Grajales, V. (2009): "How Pension Rules Affect Work and Contribution Patterns: A Behavioral Model of the Chilean Privatized Pension System," Unpublished Dissertation, University of Pennsylvania.

\section{A Solution of the retired household's problem}

The solution of the problem is derived from the period budget constraints, the terminal condition $a_{t_{D}+1}=0$ and the set of Euler Equations:

$$
\forall t \in\left\{t_{R}, \ldots t_{D}-1\right\} \quad u^{\prime}\left(c_{t}\right)=\beta \cdot(1+r) \cdot u^{\prime}\left(c_{t+1}\right)
$$

Given the CRRA preferences, the Euler equations become:

$$
\forall t \in\left\{t_{R}, \ldots t_{D}-1\right\} \quad c_{t+1}=\beta \cdot(1+r)^{\frac{1}{\sigma}} \cdot c_{t}
$$

Let us iterate this relationship to obtain consumption at each period $c_{t}$ as a function of consumption at retirement $c_{t_{R}}$ :

$$
\forall t \in\left\{t_{R}, \ldots t_{D}-1\right\} \quad c_{t}=c_{t_{R}} \cdot(\beta(1+r))^{\frac{t-t_{R}}{\sigma}}
$$


A vertical summation of the period budget constraints, premultiplied by $\left(\frac{1}{1+r}\right)^{t-t_{R}}$, yields:

$$
a_{t_{R}}=\sum_{t=t_{R}}^{t_{D}}\left(\frac{1}{1+r}\right)^{t-t_{R}} c_{t}
$$

The solution is characterized by consumption at each period as a function of assets at retirement:

$$
\begin{gathered}
c_{t_{R}}=a_{t_{R}} \cdot \frac{1}{\sum_{t=t_{R}}^{t_{D}}\left(\frac{p_{t}}{p_{t_{R}}} \cdot\left(\beta(1+r)^{1-\sigma}\right)^{t-t_{R}}\right)^{\frac{1}{\sigma}}} \\
\forall t \in\left\{t_{R}, \ldots t_{D}-1\right\} \quad c_{t}=c_{t_{R}} \cdot(\beta(1+r))^{\frac{t-t_{R}}{\sigma}}
\end{gathered}
$$

\section{B Tables and Figures}


Table 1: Parameter Estimates: Preferences

\begin{tabular}{|c|c|c|}
\hline Name & Symbol & Value \\
\hline Discount factor & $\rho$ & $\begin{array}{c}0.067 \\
(0.00155)\end{array}$ \\
\hline Intertemporal Elasticity of Substitution & $\sigma$ & $\begin{array}{c}1.559 \\
(0.03661)\end{array}$ \\
\hline Value of leisure (Female - type 1) & $\delta^{W}$ & $\begin{array}{c}0.085 \\
(0.00329)\end{array}$ \\
\hline Value of leisure (Female - type 2) & $\delta^{W}$ & $\begin{array}{c}0.044 \\
(0.00219)\end{array}$ \\
\hline Value of leisure (Female - type 3) & $\delta^{W}$ & $\begin{array}{c}0.180 \\
(0.01715)\end{array}$ \\
\hline Value of leisure (Male - type 1) & $\delta^{H}$ & $\begin{array}{c}0.095 \\
(0.00657)\end{array}$ \\
\hline Value of leisure (Male - type 2) & $\delta^{H}$ & $\begin{array}{c}0.009 \\
(0.00219)\end{array}$ \\
\hline Value of leisure (Male - type 3) & $\delta^{H}$ & $\begin{array}{c}0.008 \\
(0.01890)\end{array}$ \\
\hline Cost of switching sectors (Male) & $\phi_{s}^{H}$ & $\begin{array}{c}0.074 \\
(0.00438)\end{array}$ \\
\hline Cost of switching sectors (Female) & $\phi_{s}^{W}$ & $\begin{array}{c}0.262 \\
(0.01694)\end{array}$ \\
\hline Cost of returning to work (Male) & $\phi_{a}^{H}$ & $\begin{array}{c}0.258 \\
(0.02044)\end{array}$ \\
\hline Cost of returning to work (Female) & $\phi_{a}^{W}$ & $\begin{array}{c}0.724 \\
(0.05000)\end{array}$ \\
\hline Standard Deviation of Leisure shocks (Male) & $\sigma_{P}^{H}$ & $\begin{array}{c}0.001 \\
(0.00007)\end{array}$ \\
\hline Standard Deviation of Leisure shocks (Female) & $\sigma_{P}^{W}$ & $\begin{array}{c}0.001 \\
(0.00006)\end{array}$ \\
\hline
\end{tabular}


Table 2: Parameter Estimates: Earnings Offers

\begin{tabular}{lccc}
\hline \hline Name & Symbol & Male & Female \\
\hline Covered sector constant & $\alpha_{C}^{i}$ & -0.565 & -1.364 \\
& & $(0.02500)$ & $(0.02592)$ \\
Uncovered sector constant & $\alpha_{U}^{i}$ & -1.060 & -1.789 \\
& & $(0.01180)$ & $(0.01373)$ \\
Cohort effect & $\theta^{c}$ & $0.050^{*}$ & $0.050^{*}$ \\
& & $(0.00490)$ & $(0.00490)$ \\
Returns to education (Covered sector) & $\theta_{E, C}^{i}$ & 0.085 & 0.067 \\
& & $(0.00910)$ & $(0.01522)$ \\
Returns to education (Uncovered sector) & $\theta_{E, U}^{i}$ & 0.119 & 0.085 \\
& & $(0.00890)$ & $(0.01411)$ \\
Returns to covered experience & $\theta_{X, C}^{i}$ & 0.020 & 0.045 \\
& & $(0.00098)$ & $(0.00190)$ \\
Returns to uncovered experience & $\theta_{X, U}^{i}$ & 0.023 & 0.039 \\
& & $(0.00110)$ & $(0.00190)$ \\
Experience-schooling interaction & $\theta_{X, E}^{i}$ & 0.003 & 0.005 \\
& & $(0.00030)$ & $(0.00035)$ \\
Experience-schooling interaction (College graduates) & $\theta_{X, E}^{i}$ & 0.018 & 0.005 \\
& $\tau_{X P}^{j}$ & $(0.00110)$ & $(0.00094)$ \\
Experience transferability & $0.971^{*}$ & $0.971^{*}$ \\
& & $(0.11114)$ & $(0.11114)$ \\
Sd of shocks to earnings offers (Covered) & $\sigma_{C}^{i}$ & 0.219 & 0.208 \\
& & $(0.01296)$ & $(0.03129)$ \\
Sd of shocks to earning offers (Uncovered) & $\sigma_{U}^{i}$ & 0.265 & 0.134 \\
& & $(0.02324)$ & $(0.02221)$ \\
\hline Standard errors are in parentheses,
\end{tabular}

Standard errors are in parentheses.

* Cohort effects and experience transferability were constrained to be equal across

gender and sectors to reduce the number of parameters to be estimated.

Table 3: Parameter Estimates: Probability of Receiving a Covered Offer

\begin{tabular}{lccc}
\hline \hline Name & Symbol & Male & Female \\
\hline & & & \\
Constant & $\gamma^{i}$ & 1.999 & 2.167 \\
& & $(0.33419)$ & $(0.54840)$ \\
Schooling level & $\gamma_{E}^{i}$ & 0.999 & 0.881 \\
& & $(0.17035)$ & $(0.25461)$ \\
Covered Job at t-1 & $\gamma_{\text {Cov }}^{i}$ & 0.098 & 0.995 \\
& & $(0.0457)$ & $(0.41108)$ \\
Covered experience & $\gamma_{X P}^{i}$ & 0.029 & 0.072 \\
& & $(0.00876)$ & $(0.02756)$ \\
\hline
\end{tabular}


Table 4: Parameter Estimates: Types Logit Parameters

\begin{tabular}{lcccc}
\hline \hline Name & Symbol & Type 1 & Type 2 & Type 3 \\
\hline Constant & $\lambda(\psi)$ & $-1.310^{*}$ & 1.899 & 0.019 \\
& & & $(0.20512)$ & $(0.06689)$ \\
Schooling level (Husband) & $\lambda_{E}^{H}(\psi)$ & $0.701^{*}$ & -0.207 & -1.203 \\
& & & $(0.06608)$ & $(0.38683)$ \\
Schooling level (Wife) & $\lambda_{E}^{W}(\psi)$ & $0.001^{*}$ & -0.339 & -1.201 \\
& & & $(0.07867)$ & $(0.28379)$ \\
Cohort & $\lambda_{E}^{C}(\psi)$ & $0.002^{*}$ & -0.298 & 1.042 \\
& & & $(0.05728)$ & $(0.10012)$ \\
\hline
\end{tabular}

Standard errors are in parentheses.

* Since the type probabilities must sum to one, the coefficients of only two out of

three Types can be identified so Type 1's coefficients were held fixed through estimation.

Table 5: Model Fit: Private Savings

\begin{tabular}{lcc}
\hline \hline & Data & Model \\
\hline mean & & \\
sd & 6.46 & 7.35 \\
p10 & 8.41 & 7.80 \\
p50 & -.06 & .09 \\
p90 & 4.12 & 5.45 \\
& 16.25 & 16.54 \\
By Age & & \\
\hline 20 & & \\
25 & 3.64 & 4.03 \\
30 & 4.03 & 5.80 \\
35 & 5.46 & 6.94 \\
40 & 6.80 & 7.80 \\
45 & 8.09 & 8.39 \\
& 9.47 & 8.22
\end{tabular}

By Education of the Husband

\begin{tabular}{lcc} 
No HS & 4.75 & 4.98 \\
HS dropout & 5.51 & 6.75 \\
HS grad & 7.04 & 7.84 \\
College grad & 11.86 & 11.81 \\
\hline
\end{tabular}


Table 6: Model Fit: Pension savings

\begin{tabular}{lcccc}
\hline \hline & \multicolumn{2}{c}{ Husband } & \multicolumn{2}{c}{ Wife } \\
& Data & Model & Data & Model \\
\hline mean & & & & \\
sd & 1.21 & 1.22 & .29 & .28 \\
p10 & 2.22 & 1.72 & .90 & .87 \\
p50 & 0 & 0 & 0 & 0 \\
p90 & .39 & .58 & 0 & 0 \\
& 3.20 & 3.35 & 0.75 & 0.78 \\
By Age & & & & \\
\hline 20 & & & & \\
25 & .18 & .29 & .07 & .10 \\
30 & .61 & .70 & .17 & .19 \\
35 & 1.50 & 1.58 & .34 & .35 \\
40 & 2.91 & 2.73 & .64 & .57 \\
& 4.91 & 3.80 & 1.15 & .85 \\
By Education of the Husband & & & & \\
No HS & & & & \\
HS dropout & .50 & .57 & .07 & .23 \\
HS grad & .91 & 1.03 & .16 & .26 \\
College grad & 1.59 & 1.48 & .42 & .32 \\
& 2.75 & 2.29 & .56 & .38 \\
\hline
\end{tabular}

Table 7: Model Fit: Household Labor Force Participation

\begin{tabular}{lcc}
\hline \hline & Data & Model \\
\hline Husband's/Wife's sector & & \\
Covered/Covered & $18.0 \%$ & $20.0 \%$ \\
Covered/Uncovered & $7.5 \%$ & $8.6 \%$ \\
Covered/Home & $40.2 \%$ & $41.7 \%$ \\
Uncovered/Covered & $6.3 \%$ & $8.6 \%$ \\
Uncovered/Uncovered & $4.9 \%$ & $3.6 \%$ \\
Uncovered/Home & $16.7 \%$ & $14.5 \%$ \\
Home/Covered & $1.4 \%$ & $2.0 \%$ \\
Home/Uncovered & $0.9 \%$ & $0.3 \%$ \\
Home/Home & $4.1 \%$ & $0.5 \%$ \\
& & \\
\hline
\end{tabular}


Table 8: Model fit: Labor sector choice by age

\begin{tabular}{|c|c|c|c|c|}
\hline & \multicolumn{2}{|c|}{ Husbands } & \multicolumn{2}{|c|}{ Wives } \\
\hline & Data & Model & Data & Model \\
\hline \multicolumn{5}{|l|}{ Covered Sector } \\
\hline 20 & $66.0 \%$ & $63.9 \%$ & $30.8 \%$ & $23.9 \%$ \\
\hline 25 & $71.8 \%$ & $69.0 \%$ & $28.5 \%$ & $27.6 \%$ \\
\hline 30 & $68.3 \%$ & $70.2 \%$ & $26.1 \%$ & $27.0 \%$ \\
\hline 35 & $65.1 \%$ & $69.5 \%$ & $25.4 \%$ & $24.8 \%$ \\
\hline 40 & $60.7 \%$ & $69.7 \%$ & $24.4 \%$ & $23.9 \%$ \\
\hline 45 & $61.4 \%$ & $67.8 \%$ & $20.5 \%$ & $22.7 \%$ \\
\hline \multicolumn{5}{|l|}{ Uncovered Sector } \\
\hline 20 & $26.2 \%$ & $31.4 \%$ & $10.4 \%$ & $8.7 \%$ \\
\hline 25 & $25.2 \%$ & $28.0 \%$ & $9.9 \%$ & $10.4 \%$ \\
\hline 30 & $28.4 \%$ & $26.2 \%$ & $11.2 \%$ & $12.4 \%$ \\
\hline 35 & $30.7 \%$ & $27.2 \%$ & $15.0 \%$ & $13.3 \%$ \\
\hline 40 & $33.8 \%$ & $26.4 \%$ & $18.0 \%$ & $10.1 \%$ \\
\hline 45 & $31.5 \%$ & $27.1 \%$ & $19.9 \%$ & $10.6 \%$ \\
\hline \multicolumn{5}{|l|}{ Home } \\
\hline 20 & $7.8 \%$ & $4.7 \%$ & $58.8 \%$ & $67.3 \%$ \\
\hline 25 & $3.1 \%$ & $3.0 \%$ & $61.6 \%$ & $62.1 \%$ \\
\hline 30 & $3.3 \%$ & $3.6 \%$ & $62.8 \%$ & $60.6 \%$ \\
\hline 35 & $4.3 \%$ & $3.3 \%$ & $59.6 \%$ & $61.9 \%$ \\
\hline 40 & $5.5 \%$ & $3.9 \%$ & $57.6 \%$ & $66.1 \%$ \\
\hline 45 & $7.1 \%$ & $5.2 \%$ & $59.6 \%$ & $66.7 \%$ \\
\hline
\end{tabular}


Table 9: Model fit: Labor sector choice by schooling level

\begin{tabular}{rrrrr}
\hline \hline & \multicolumn{2}{c}{ Husbands } & \multicolumn{2}{c}{ Wives } \\
& Data & Model & Data & Model \\
\hline Covered Sector & & & & \\
No H.S. & $51.4 \%$ & $63.7 \%$ & $13.4 \%$ & $14.8 \%$ \\
H.S. dropout & $63.4 \%$ & $66.8 \%$ & $19.3 \%$ & $18.5 \%$ \\
H.S. grad & $75.2 \%$ & $71.2 \%$ & $34.3 \%$ & $31.6 \%$ \\
Col. Grad & $77.6 \%$ & $76.4 \%$ & $61.5 \%$ & $64.9 \%$ \\
& & & & \\
Uncovered Sector & & & & \\
No H.S. & $42.0 \%$ & $27.6 \%$ & $10.7 \%$ & $8.5 \%$ \\
H.S. dropout & $32.8 \%$ & $29.5 \%$ & $14.4 \%$ & $11.3 \%$ \\
H.S. grad & $21.0 \%$ & $26.8 \%$ & $11.7 \%$ & $12.3 \%$ \\
Col. Grad & $14.8 \%$ & $23.1 \%$ & $13.5 \%$ & $7.8 \%$ \\
& & & & \\
Home No H.S. & $6.6 \%$ & $8.7 \%$ & $75.9 \%$ & $76.7 \%$ \\
H.S. dropout & $3.8 \%$ & $3.7 \%$ & $66.3 \%$ & $70.2 \%$ \\
H.S. grad & $3.8 \%$ & $2.0 \%$ & $54.0 \%$ & $56.1 \%$ \\
Col. Grad & $7.6 \%$ & $0.5 \%$ & $25.0 \%$ & $27.4 \%$ \\
& & & & \\
\hline
\end{tabular}


Table 10: Model fit: Distribution of years worked in covered jobs/total years worked

\begin{tabular}{ccc}
\hline \hline & Data & Model \\
\hline Husbands under age 35 & & \\
$0-25 \%$ & $18.8 \%$ & $18.8 \%$ \\
$25-50 \%$ & $8.1 \%$ & $6.2 \%$ \\
$50-75 \%$ & $14.3 \%$ & $16.6 \%$ \\
$75-99 \%$ & $23.0 \%$ & $29.7 \%$ \\
$100 \%$ & $35.7 \%$ & $28.8 \%$ \\
& & \\
Husbands over age 35 & & \\
$0-25 \%$ & $12.7 \%$ & $15.9 \%$ \\
$25-50 \%$ & $7.3 \%$ & $6.8 \%$ \\
$50-75 \%$ & $13.4 \%$ & $15.4 \%$ \\
$75-99 \%$ & $17.5 \%$ & $20.9 \%$ \\
$100 \%$ & $49.1 \%$ & $41.0 \%$ \\
& & \\
Wives under age 35 & & \\
$0-25 \%$ & $24.1 \%$ & $32.1 \%$ \\
$25-50 \%$ & $8.8 \%$ & $7.9 \%$ \\
$50-75 \%$ & $9.2 \%$ & $12.8 \%$ \\
$75-99 \%$ & $10.1 \%$ & $10.5 \%$ \\
$100 \%$ & $47.8 \%$ & $36.7 \%$ \\
& & \\
Wives over age 35 & & \\
$0-25 \%$ & $15.2 \%$ & $22.5 \%$ \\
$25-50 \%$ & $6.8 \%$ & $5.4 \%$ \\
$50-75 \%$ & $10.9 \%$ & $8.6 \%$ \\
$75-99 \%$ & $11.0 \%$ & $8.0 \%$ \\
$100 \%$ & $56.1 \%$ & $55.5 \%$ \\
& & \\
\hline
\end{tabular}

Table 11: Model fit: Transitions between labor sector choices (age 45-50)

\begin{tabular}{llcccc}
\hline \hline & & \multicolumn{2}{c}{ Husbands } & \multicolumn{2}{c}{ Wives } \\
& & Data & Model & Data & Model \\
\hline \multirow{2}{*}{ From Covered... } & ... to Covered & $93.5 \%$ & $94.2 \%$ & $83.7 \%$ & $90.8 \%$ \\
& ...to Uncovered & $5.4 \%$ & $4.9 \%$ & $9.3 \%$ & $0.8 \%$ \\
& ..to Inactive & $1.1 \%$ & $0.9 \%$ & $7.0 \%$ & $8.5 \%$ \\
From Inactive... & ... to Covered & $27.3 \%$ & $18.2 \%$ & $3.9 \%$ & $0.8 \%$ \\
& ...to Uncovered & $13.6 \%$ & $16.7 \%$ & $8.7 \%$ & $3.2 \%$ \\
From Uncovered... & ...to Inactive & $59.1 \%$ & $65.2 \%$ & $87.4 \%$ & $95.9 \%$ \\
& ..to Covered & $12.9 \%$ & $11.5 \%$ & $5.6 \%$ & $2.2 \%$ \\
& ..to Uncovered & $83.0 \%$ & $81.7 \%$ & $78.7 \%$ & $78.8 \%$ \\
& ...to Inactive & $4.1 \%$ & $6.8 \%$ & $15.7 \%$ & $19.0 \%$ \\
& & & & & \\
\hline
\end{tabular}


Table 12: Model fit: Transitions between labor sector choices (age 25-30)

\begin{tabular}{llcccc}
\hline \hline & & \multicolumn{2}{c}{ Husbands } & \multicolumn{2}{c}{ Wives } \\
& & Data & Model & Data & Model \\
\hline \multirow{3}{*}{ From Covered... } & ...to Covered & $95.5 \%$ & $91.5 \%$ & $84.2 \%$ & $94.5 \%$ \\
& ...to Uncovered & $3.7 \%$ & $7.4 \%$ & $2.5 \%$ & $0.7 \%$ \\
& ...to Inactive & $0.8 \%$ & $1.1 \%$ & $13.3 \%$ & $4.8 \%$ \\
From Inactive... & ...to Covered & $31.5 \%$ & $31.8 \%$ & $4.2 \%$ & $3.2 \%$ \\
& ...to Uncovered & $6.6 \%$ & $23.1 \%$ & $2.4 \%$ & $3.7 \%$ \\
From Uncovered... & ...to Inactive & $61.9 \%$ & $45.0 \%$ & $93.4 \%$ & $93.1 \%$ \\
& ..to Covered & $9.6 \%$ & $21.2 \%$ & $5.6 \%$ & $3.0 \%$ \\
& ...to Uncovered & $89.8 \%$ & $76.4 \%$ & $79.2 \%$ & $78.9 \%$ \\
& ...to Inactive & $0.5 \%$ & $2.4 \%$ & $15.2 \%$ & $18.1 \%$ \\
& & & & & \\
\hline
\end{tabular}

Table 13: Model Fit: Earnings (Husbands)

\begin{tabular}{lcccc}
\hline \hline & \multicolumn{2}{c}{ Covered Sector } & \multicolumn{2}{c}{ Uncovered Sector } \\
& Data & Model & Data & Model \\
\hline Distribution & & & & \\
mean & 2.92 & 2.97 & 2.41 & 2.63 \\
sd & 2.13 & 1.99 & 2.13 & 2.00 \\
p10 & 1.38 & 1.20 & 0.72 & 0.81 \\
p50 & 2.4 & 2.50 & 1.80 & 2.14 \\
p90 & 5.35 & 5.26 & 4.71 & 5.04 \\
& & & & \\
By Age & & & & \\
20 & 2.08 & 2.41 & 1.57 & 2.44 \\
25 & 2.59 & 2.65 & 1.91 & 2.57 \\
30 & 2.96 & 2.82 & 2.54 & 2.59 \\
35 & 2.91 & 3.05 & 2.54 & 2.66 \\
40 & 3.21 & 3.31 & 2.39 & 2.67 \\
45 & 3.64 & 3.49 & 3.18 & 2.82 \\
& & & & \\
By Schooling level & & & & \\
No HS & 1.77 & 1.57 & 1.42 & 1.11 \\
HS dropout & 2.18 & 2.32 & 2.13 & 2.00 \\
HS grad & 3.29 & 3.35 & 3.09 & 3.34 \\
College grad & 6.44 & 5.96 & 5.50 & 5.35 \\
& & & & \\
\hline
\end{tabular}


Table 14: Model Fit: Earnings (Wives)

\begin{tabular}{lcccc}
\hline \hline & \multicolumn{2}{c}{ Covered Sector } & \multicolumn{2}{c}{ Uncovered Sector } \\
& Data & Model & Data & Model \\
\hline Distribution & & & & \\
mean & 1.78 & 1.68 & 1.13 & 0.86 \\
sd & 1.21 & 1.35 & 1.03 & 0.62 \\
p10 & 0.41 & 0.54 & 0.15 & 0.31 \\
p50 & 1.56 & 1.33 & 0.84 & 0.70 \\
p90 & 3.60 & 3.23 & 2.40 & 1.58 \\
& & & & \\
By Age & & & & \\
20 & 1.40 & 1.06 & 0.77 & 0.72 \\
25 & 1.94 & 1.30 & 1.14 & 0.77 \\
30 & 2.01 & 1.57 & 0.96 & 0.80 \\
35 & 1.66 & 1.77 & 1.07 & 0.84 \\
40 & 1.62 & 2.09 & 1.21 & 0.98 \\
45 & 1.97 & 2.4 & 1.66 & 1.01 \\
& & & & \\
By Schooling level & & & & \\
No HS & 0.93 & 0.87 & 0.72 & 0.44 \\
HS dropout & 1.23 & 1.18 & 0.96 & 0.73 \\
HS grad & 1.92 & 1.77 & 1.32 & 0.95 \\
College grad & 2.89 & 2.82 & 2.31 & 1.77 \\
& & & & \\
\hline
\end{tabular}


Table 15: Summary statistics

\begin{tabular}{|c|c|c|c|}
\hline & Husband & Wife & $\begin{array}{l}\text { Household } \\
\end{array}$ \\
\hline \multicolumn{4}{|l|}{ Private assets (million pesos) } \\
\hline median at 25 & - & - & 1.5 \\
\hline median at 35 & - & - & 4.8 \\
\hline median at 45 & - & - & 8 \\
\hline \multicolumn{4}{|l|}{ Pension savings (million pesos) } \\
\hline median at 25 & 0.3 & 0.1 & - \\
\hline median at 35 & 2.3 & 0.3 & - \\
\hline median at 45 & 4.5 & 0.0 & - \\
\hline \multicolumn{4}{|c|}{ Median annual earnings (thousand pesos) } \\
\hline Covered sector jobs & 2409 & 1547 & - \\
\hline Uncovered sector jobs & 1680 & 720 & - \\
\hline \multicolumn{4}{|l|}{ Schooling level (sample) } \\
\hline No High school & $15 \%$ & $15 \%$ & - \\
\hline High school dropouts & $36 \%$ & $36 \%$ & - \\
\hline High school graduates & $43 \%$ & $45 \%$ & - \\
\hline College graduates & $6 \%$ & $4 \%$ & - \\
\hline \multicolumn{4}{|c|}{ Schooling level (Uncovered sector workers) } \\
\hline No High school & $24 \%$ & $14 \%$ & - \\
\hline High school dropouts & $42 \%$ & $40 \%$ & - \\
\hline High school graduates & $31 \%$ & $42 \%$ & - \\
\hline College graduates & $2 \%$ & $5 \%$ & - \\
\hline \multicolumn{4}{|l|}{ Joint labor sector choice } \\
\hline \multicolumn{4}{|l|}{ Husband's/Wife's sector } \\
\hline Covered/Covered & - & - & $18 \%$ \\
\hline Covered/Uncovered & - & - & $8 \%$ \\
\hline Covered/Home & - & - & $40 \%$ \\
\hline Uncovered/Covered & - & - & $6 \%$ \\
\hline Uncovered/Uncovered & - & - & $5 \%$ \\
\hline Uncovered/Home & - & - & $17 \%$ \\
\hline Home/Covered & - & - & $1 \%$ \\
\hline Home/Uncovered & - & - & $1 \%$ \\
\hline Home/Home & - & - & $4 \%$ \\
\hline \multicolumn{4}{|l|}{ Years worked in covered jobs } \\
\hline$>75 \%$ of total number of years & $60 \%$ & $58 \%$ & - \\
\hline$<25 \%$ of total number of years & $20 \%$ & $25 \%$ & - \\
\hline
\end{tabular}


Table 16: Person-period observations by age group and birth cohort

\begin{tabular}{|c|rrrrrr|r|}
\hline & \multicolumn{7}{|c|}{ Age of the Husband } \\
\hline Birth cohort & 25 & 30 & 35 & 40 & 45 & 50 & Total \\
\hline 1955 & 2,775 & 2,776 & 2,780 & 2,780 & 2,460 & 321 & 13,892 \\
1965 & 3,282 & 3,280 & 3,280 & 2,888 & 411 & 0 & 13,141 \\
1970 & 2,840 & 2,840 & 2,499 & 355 & 0 & 0 & 8,534 \\
1975 & 2,402 & 2,160 & 307 & 0 & 0 & 0 & 4,869 \\
1980 & 1,621 & 250 & 0 & 0 & 0 & 0 & 1,871 \\
\hline Total & 12,920 & 11,306 & 8,866 & 6,023 & 2,871 & 321 & 42,307 \\
\hline
\end{tabular}

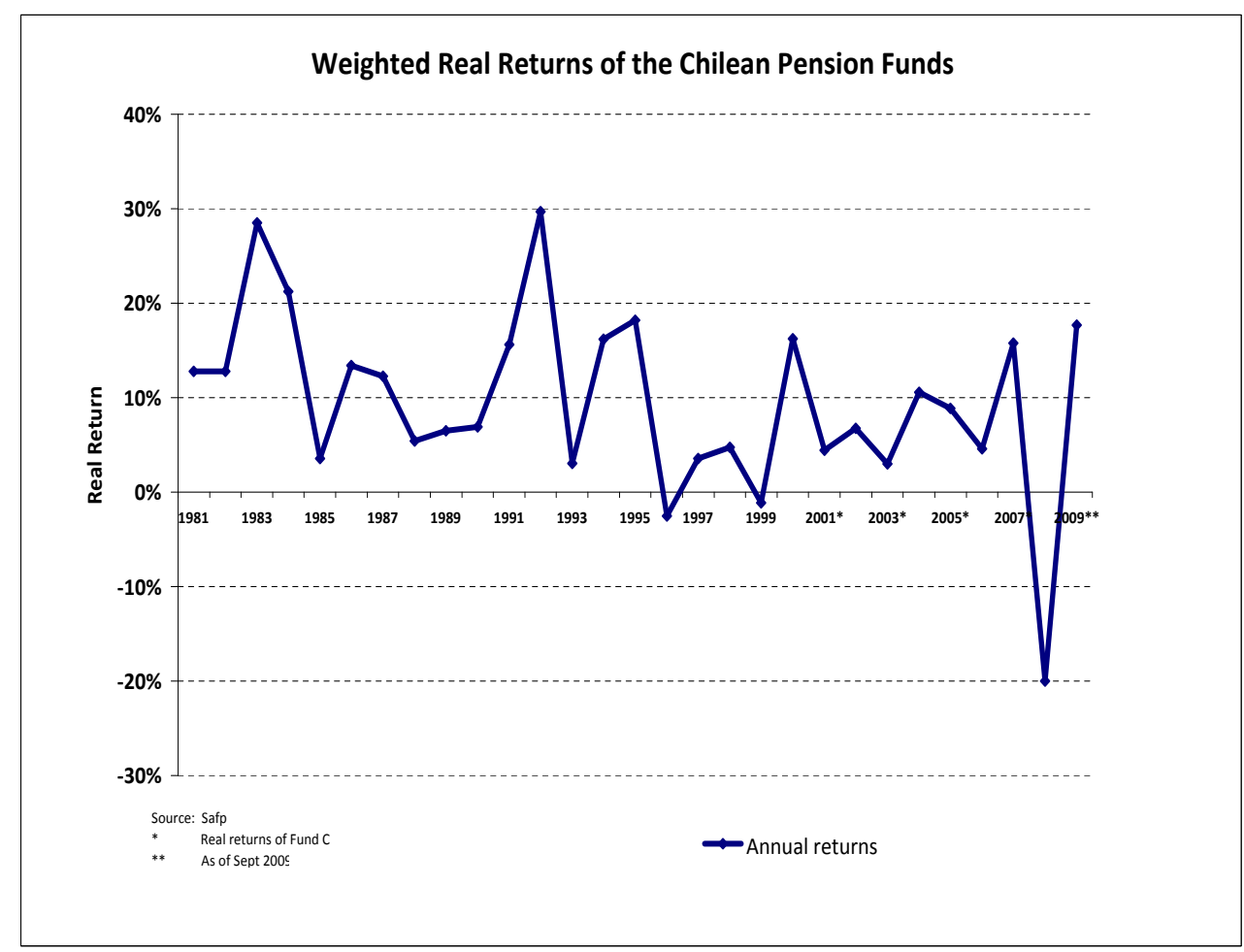

Figure 2: Rentability of the Chilean Pension Funds 1981-2009 
Table 17: Changing the contribution rate

\begin{tabular}{|c|c|c|c|c|c|c|c|}
\hline \multicolumn{8}{|l|}{ Policy Parameters } \\
\hline Contribution rate & $5 \%$ & $7.5 \%$ & $10 \%$ & $12.5 \%$ & $15 \%$ & $17.5 \%$ & $20 \%$ \\
\hline \multicolumn{8}{|l|}{ Welfare Pension } \\
\hline Level (monthly pesos) & 48000 & 48000 & 48000 & 48000 & 48000 & 48000 & 48000 \\
\hline Taper rate $(\%)$ & 100 & 100 & 100 & 100 & 100 & 100 & 100 \\
\hline \multicolumn{8}{|l|}{ Minimum Pension } \\
\hline Level (monthly pesos) & 105000 & 105000 & 105000 & 105000 & 105000 & 105000 & 105000 \\
\hline Eligibility (yrs) & 20 & 20 & 20 & 20 & 20 & 20 & 20 \\
\hline Pension returns projection (\%) & 5.98 & 5.98 & 5.98 & 5.98 & 5.98 & 5.98 & 5.98 \\
\hline \multicolumn{8}{|l|}{ Outcomes } \\
\hline \multicolumn{8}{|l|}{ Husbands' coverage } \\
\hline$\%$ covered & 0.744 & 0.723 & 0.699 & 0.677 & 0.660 & 0.634 & 0.611 \\
\hline$\%$ uncovered & 0.234 & 0.252 & 0.272 & 0.293 & 0.310 & 0.334 & 0.356 \\
\hline$\%$ inactive & 0.022 & 0.024 & 0.028 & 0.029 & 0.030 & 0.0 .31 & 0.032 \\
\hline$\%$ density under $75 \%$ & 42.910 & 43.880 & 45.580 & 46.610 & 48.110 & 49.450 & 50.910 \\
\hline \multicolumn{8}{|l|}{ Wives' coverage } \\
\hline$\%$ covered & 0.334 & 0.327 & 0.303 & 0.276 & 0.260 & 0.246 & 0.237 \\
\hline$\%$ uncovered & 0.101 & 0.111 & 0.125 & 0.136 & 0.150 & 0.151 & 0.157 \\
\hline$\%$ inactive & 0.563 & 0.561 & 0.571 & 0.587 & 0.590 & 0.601 & 0.605 \\
\hline$\%$ lifetime density under $75 \%$ & 85.740 & 85.760 & 86.440 & 86.480 & 86.570 & 86.780 & 86.380 \\
\hline \multicolumn{8}{|l|}{ Welfare Pension } \\
\hline \% eligible husbands & 4.010 & 3.960 & 3.620 & 3.620 & 4.100 & 4.100 & 4.480 \\
\hline$\%$ eligible wives & 6.720 & 4.770 & 3.580 & 3.580 & 4.100 & 4.150 & 4.480 \\
\hline Projected liabilities* & 903300 & 711650 & 439200 & 569450 & 655750 & 646250 & 709035 \\
\hline \multicolumn{8}{|l|}{ Minimum Pension } \\
\hline$\%$ eligible husbands & 35.190 & 7.300 & 1.530 & 0.240 & 0.190 & 0.100 & 0.100 \\
\hline$\%$ eligible wives & 21.220 & 9.540 & 4.430 & 1.570 & 0.860 & 0.520 & 0.380 \\
\hline Projected liabilities* & 3905347 & 936585 & 216100 & 117100 & 80100 & 45450 & 36300 \\
\hline \multicolumn{8}{|l|}{ Mean Private savings } \\
\hline \multirow{2}{*}{\multicolumn{8}{|c|}{ Age profile }} \\
\hline & & & & & & & \\
\hline 25 & 4.837 & 4.600 & 4.526 & 4.442 & 4.370 & 4.297 & 4.240 \\
\hline 35 & 9.828 & 8.600 & 8.370 & 7.860 & 7.490 & 7.178 & 6.820 \\
\hline 45 & 19.824 & 17.750 & 17.430 & 16.610 & 16.210 & 15.780 & 15.120 \\
\hline 55 & 38.670 & 35.470 & 33.770 & 31.900 & 30.720 & 29.250 & 27.890 \\
\hline 65 & 74.849 & 47.250 & 42.230 & 38.370 & 35.410 & 32.930 & 31.130 \\
\hline \multicolumn{8}{|l|}{ Mean Male Pension savings } \\
\hline \multirow{2}{*}{\multicolumn{8}{|c|}{$\begin{array}{l}\text { Age profile } \\
\text { Agection }\end{array}$}} \\
\hline & & & & & & & \\
\hline 25 & 0.191 & 0.587 & 0.804 & 1.014 & 1.220 & 1.409 & 1.589 \\
\hline 35 & 0.986 & 2.350 & 3.400 & 4.407 & 5.340 & 6.249 & 7.069 \\
\hline 45 & 2.674 & 6.010 & 8.758 & 11.400 & 13.860 & 16.240 & 18.400 \\
\hline 55 & 5.708 & 12.890 & 18.868 & 24.000 & 30.020 & 35.160 & 39.860 \\
\hline 65 & 9.173 & 20.790 & 30.520 & 40.020 & 48.790 & 57.190 & 64.870 \\
\hline \multicolumn{8}{|l|}{ Mean Female Pension savings } \\
\hline 2004 Cross-section & 0.316 & 0.522 & 0.713 & 0.886 & 1.060 & 1.212 & 1.370 \\
\hline \multicolumn{8}{|l|}{ Age profile } \\
\hline 25 & 0.000 & 0.186 & 0.230 & 0.278 & 0.320 & 0.365 & 0.400 \\
\hline 35 & 0.027 & 0.626 & 0.861 & 1.070 & 1.280 & 1.470 & 1.665 \\
\hline 45 & 0.135 & 1.640 & 2.290 & 2.873 & 3.450 & 3.980 & 4.516 \\
\hline 55 & 0.353 & 3.688 & 5.152 & 6.457 & 7.780 & 8.970 & 10.232 \\
\hline 65 & 0.592 & 6.050 & 8.440 & 10.610 & 12.820 & 14.830 & 17.010 \\
\hline \multicolumn{8}{|l|}{ Mean Total savings } \\
\hline 2004 Cross-section & 9.748 & 9.901 & 10.782 & 11.463 & 12.230 & 12.966 & 13.600 \\
\hline Age profile & & & & & & & \\
\hline 25 & 3.384 & 5.373 & 5.560 & 5.734 & 5.900 & 6.071 & 6.229 \\
\hline 35 & 8.676 & 11.576 & 12.631 & 13.337 & 14.100 & 14.897 & 15.554 \\
\hline 45 & 15.909 & 25.400 & 28.478 & 30.883 & 33.530 & 36.000 & 38.036 \\
\hline 55 & 35.571 & 52.048 & 57.790 & 62.357 & 68.500 & 73.380 & 77.982 \\
\hline 65 & 62.696 & 74.090 & 81.190 & 89.000 & 97.030 & 104.950 & 113.010 \\
\hline
\end{tabular}

*Present value in 2004 of payments made to workers in the sample until their death, per capita 
Table 18: Effect of an increase in the contribution rate on the distribution of contribution densities

\begin{tabular}{lccc}
\hline \hline Contribution rate & $\mathbf{1 0 \%}$ & $\mathbf{1 5 \%}$ & $\Delta$ \\
& & & \\
Husbands' contribution densities & & & \\
$0-25 \%$ & $20.1 \%$ & $25.0 \%$ & $4.9 \%$ \\
$25-50 \%$ & $11.0 \%$ & $11.7 \%$ & $0.8 \%$ \\
$50-75 \%$ & $14.6 \%$ & $11.4 \%$ & $-3.2 \%$ \\
$75-100 \%$ & $54.3 \%$ & $51.9 \%$ & $-2.5 \%$ \\
Total & $100.0 \%$ & $100.0 \%$ & \\
& & & \\
Wives' contribution densities & & & \\
$0-25 \%$ & $66.5 \%$ & $73.8 \%$ & $7.3 \%$ \\
$25-50 \%$ & $12.6 \%$ & $7.0 \%$ & $-5.6 \%$ \\
$50-75 \%$ & $7.7 \%$ & $5.7 \%$ & $-2.0 \%$ \\
$75-100 \%$ & $13.2 \%$ & $13.4 \%$ & $0.3 \%$ \\
Total & $100.0 \%$ & $100.0 \%$ & \\
& & & \\
\hline
\end{tabular}


Table 19: Effects of the 2008 Reform of the Minimum and Welfare Pension

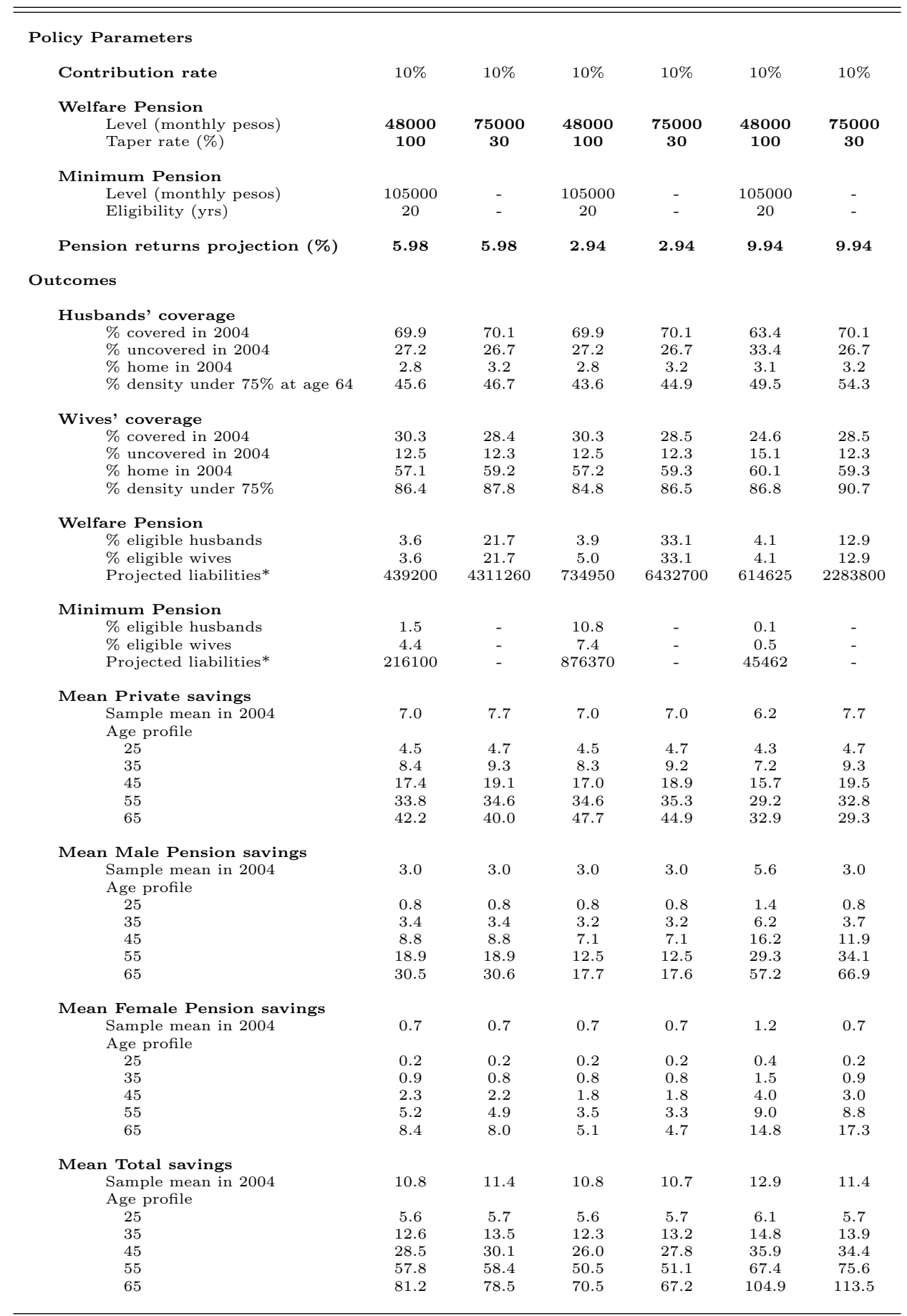

*Present value in 2004 of payments made to workers in the sample until their death, per capita 
Table 20: Effect of the 2008 reform on the coverage of Husbands, by age

\begin{tabular}{lcccc}
\hline \hline & \multicolumn{5}{c}{ \% Covered } \\
& \multicolumn{5}{c}{ Age } & Baseline & Reform & $\Delta$ & $\% \Delta$ \\
& & & & \\
$\mathbf{2 0}$ & 65.4 & 65.5 & 0.2 & $0.3 \%$ \\
$\mathbf{3 0}$ & 71.5 & 70.8 & -0.7 & $-1.0 \%$ \\
$\mathbf{4 0}$ & 69.6 & 68.9 & -0.8 & $-1.1 \%$ \\
$\mathbf{5 0}$ & 67.9 & 66.7 & -1.2 & $-1.8 \%$ \\
$\mathbf{6 0}$ & 51.7 & 46.9 & -4.8 & $-9.3 \%$ \\
& & & & \\
\hline
\end{tabular}

Table 21: Effect of the 2008 reform on the coverage of Wives, by age

\begin{tabular}{lcccc}
\hline \hline & \multicolumn{5}{c}{ \% Covered } \\
& \multicolumn{5}{c}{ Age } & Baseline & Reform & $\Delta$ & $\% \Delta$ \\
& & & & \\
$\mathbf{2 0}$ & 26.7 & 26.4 & -0.3 & $-1.1 \%$ \\
$\mathbf{3 0}$ & 29.0 & 28.1 & -0.9 & $-3.1 \%$ \\
$\mathbf{4 0}$ & 29.8 & 27.5 & -2.2 & $-7.4 \%$ \\
$\mathbf{5 0}$ & 23.5 & 20.3 & -3.2 & $-13.6 \%$ \\
$\mathbf{6 0}$ & 11.3 & 8.1 & -3.2 & $-28.3 \%$ \\
& & & & \\
\hline
\end{tabular}




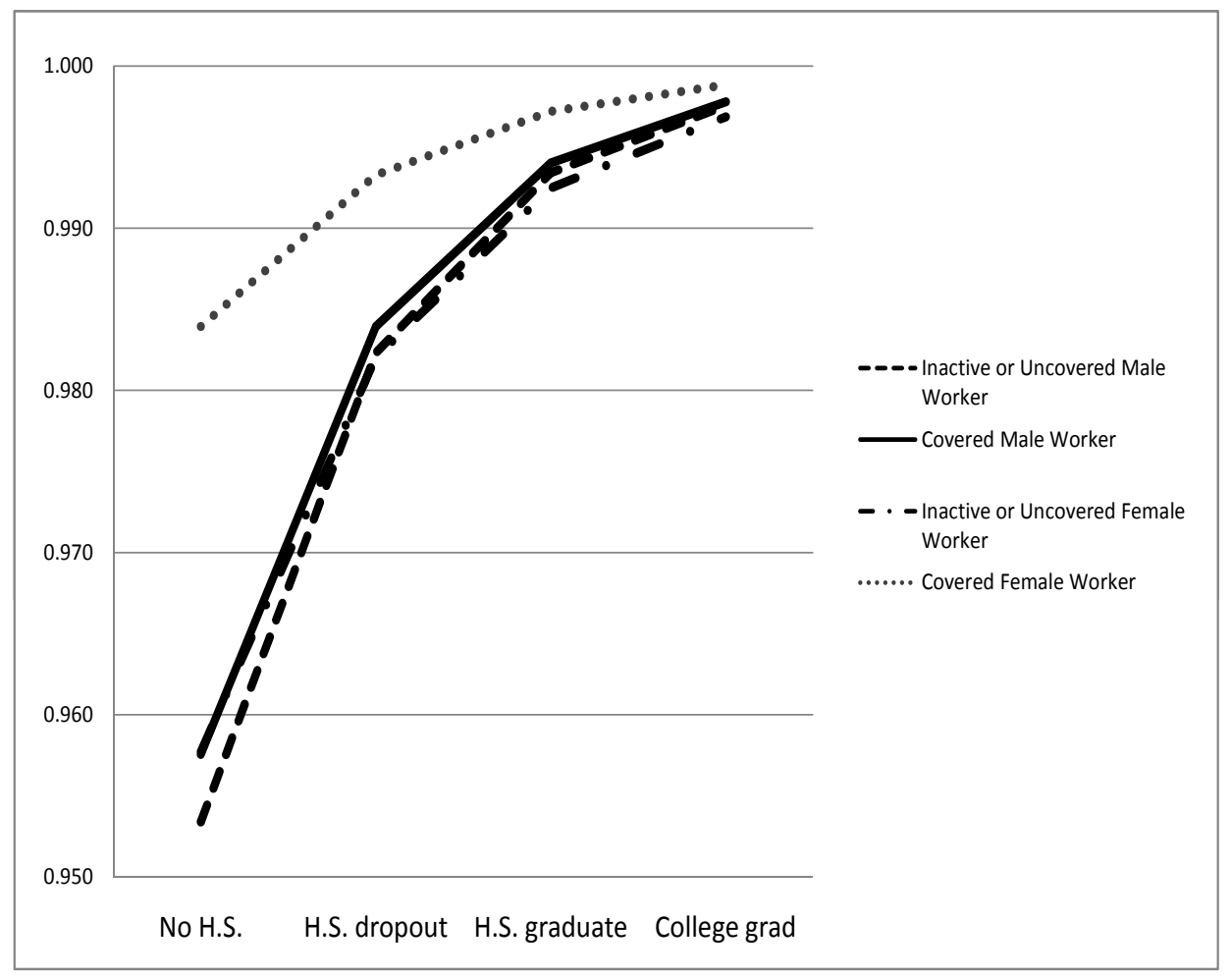

Figure 3: Probability of receiving a covered earnings offer (workers with 1 years of covered experience) 


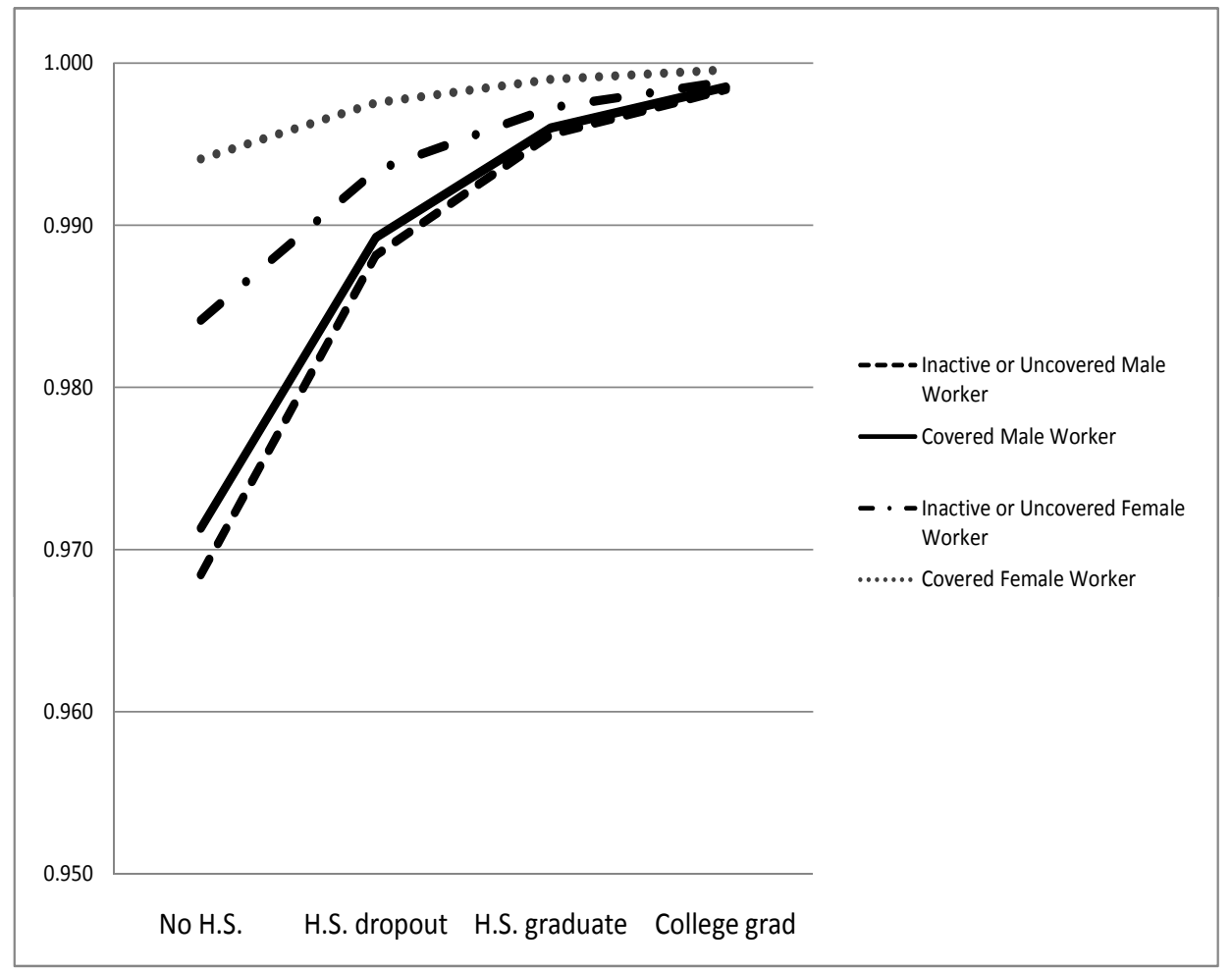

Figure 4: Probability of receiving a covered earnings offer (workers with 15 years of covered experience) 